\title{
Regulation of Cdc42 and its effectors in epithelial morphogenesis
}

\author{
Franck Pichaud $^{1,2, *}$, Rhian F. Walther ${ }^{1}$ and Francisca Nunes de Almeida ${ }^{1}$
}

\begin{abstract}
Cdc42 - a member of the small Rho GTPase family - regulates cell polarity across organisms from yeast to humans. It is an essential regulator of polarized morphogenesis in epithelial cells, through coordination of apical membrane morphogenesis, lumen formation and junction maturation. In parallel, work in yeast and Caenorhabditis elegans has provided important clues as to how this molecular switch can generate and regulate polarity through localized activation or inhibition, and cytoskeleton regulation. Recent studies have revealed how important and complex these regulations can be during epithelial morphogenesis. This complexity is mirrored by the fact that $\mathrm{Cdc} 42$ can exert its function through many effector proteins. In epithelial cells, these include atypical PKC (aPKC, also known as PKC-3), the P21activated kinase (PAK) family, myotonic dystrophy-related Cdc42 binding kinase beta (MRCK $\beta$, also known as CDC42BPB) and neural Wiskott-Aldrich syndrome protein (N-WASp, also known as WASL). Here, we review how the spatial regulation of $\mathrm{Cdc} 42$ promotes polarity and polarized morphogenesis of the plasma membrane, with a focus on the epithelial cell type.
\end{abstract}

KEY WORDS: Cdc42, Epithelia, MRCK, PAK, Par complex, Polarity

\section{Introduction}

Cell polarity - the asymmetric distribution of membrane domains, cytoskeletal components and organelles - is a fundamental feature of cells and often underpins cell behavior and function. Most organs contain epithelial cells, and understanding the mechanisms of epithelial cell morphogenesis is a key goal of cell and developmental biology. Regulation of the actomyosin and microtubule cytoskeletons, polarized delivery of proteins and variation in lipid composition all contribute to the polarization and morphogenesis of epithelial cells (Apodaca et al., 2012; Braga, 2016; Crawley et al., 2014; Jewett and Prekeris, 2018; RodriguezBoulan and Macara, 2014). The small GTPase cell division control protein 42-homolog ( $\mathrm{Cdc} 42)$ has been shown to influence all of these processes, making this factor an essential regulator of epithelial morphogenesis.

Here, we begin with an overview of $\mathrm{Cdc} 42$ and review the mechanisms of Cdc 42 function during polarized growth in the budding yeast, and polarity establishment in the Caenorhabditis elegans embryo. We then compare these mechanisms to those that drive the polarized morphogenesis of the epithelial plasma membrane, focusing on the role of $\mathrm{Cdc} 42$ during apical membrane morphogenesis, lumen formation through hollowing, and lateral junction maturation.

\footnotetext{
${ }^{1}$ MRC - Laboratory for Molecular Cell Biology, University College London, London WC1E 6BT, UK. ${ }^{2}$ Institute for the Physics of Living Systems, University College London, London WC1E 6BT, UK.

*Author for correspondence (f.pichaud@ucl.ac.uk)

(iD) F.P., 0000-0002-8393-716X
}

\section{An overview of Cdc42}

$\mathrm{Cdc} 42$ was discovered in yeast and belongs to a large family of small (20-30 kDa) GTP-binding proteins (Adams et al., 1990; Johnson and Pringle, 1990). It is part of the Ras-homologous Rho subfamily of GTPases, of which there are 20 members in humans, including the RhoA and Rac GTPases, (Hall, 2012). Rho, Rac and Cdc42 homologues are found in all eukaryotes, except for plants, which do not have a clear homologue for Cdc42. Together, the function of Rho GTPases influences most, if not all, cellular processes.

In the early 1990s, seminal work from Alan Hall and his collaborators identified Rho, Rac and $\mathrm{Cdc} 42$ as main regulators of the actomyosin cytoskeleton. These studies showed that while RhoA can promote stress fiber formation in Swiss 3T3 cells (Ridley and Hall, 1992), Rac induces the formation of lamellipodia (Ridley et al., 1992) and $\mathrm{Cdc} 42$ promotes filopodia formation in these cells (Nobes and Hall, 1995). The ability of Rho, Rac and Cdc42 to remodel and structure the actomyosin cytoskeleton in such a specific manner has profound implications for cell morphogenesis, as modulation of the cytoskeleton affects many processes, including polarity, cell adhesion, vesicular trafficking, cell migration and cytokinesis. Subsequent work has revealed how these small GTPases can elicit specific cytoskeleton regulations. For example, formation of filopodia downstream of $\mathrm{Cdc} 42$ depends on the conserved Cdc42 effector N-WASp (also known as WASL) (Aspenström et al., 1996; Kolluri et al., 1996; Symons et al., 1996) and diaphanous-related formins (Peng et al., 2003). N-WASp promotes branched F-actin organization through the Arp2/3 complex (Machesky and Insall, 1998), and formins promote linear unbranched F-actin (Pruyne et al., 2002; Sagot et al., 2002b; for a recent review see Ridley, 2015). In eukaryotes, most small GTPases can be associated with the plasma membrane upon prenylation of their C-terminal CAAX domain (Roberts et al., 2008). While a significant fraction of Cdc42 is associated with the Golgi complex (Erickson et al., 1996), it is also detected in trafficking vesicles and at the plasma membrane. At these locations, $\mathrm{Cdc} 42$ can activate downstream effectors by binding to their Cdc42and Rac-interactive binding motif (CRIB) domain (Burbelo et al., 1995; Manser et al., 1994; Symons et al., 1996). To date, at least 45 proteins encoded by the human genome have been shown to act as effectors of Cdc42 (Table S1).

An essential feature of a vast majority of Rho GTPases is that they can reversibly switch between an active, GTP-bound state (on) and an inactive, GDP-bound state (off). Consequently, these proteins are viewed as molecular switches whose on/off state can be controlled spatially and temporally in cells (Diekmann et al., 1991; Hart et al., 1991). This property is particularly relevant for Cdc42 function during cell polarity, including in epithelial cells, by allowing the localized activation of this small GTPase and its downstream effectors to promote plasma membrane differentiation, F-actin regulation and to direct trafficking (Etienne-Manneville, 2004). Spatial activation of Rho GTPases is controlled by guanine exchange factors (GEFs), GTPase-activating proteins (GAPs) and guanine nucleotide dissociation inhibitor (GDIs). GEFs activate 
small GTPases by catalyzing the exchange of GDP to GTP. Conversely, GAPs inactivate small GTPases by enabling their intrinsic GTPase activity. Additionally, in the cytosol, GDIs bind to Rho GTPases to keep them in their inactive, GDP bound state. Up to 82 GEFs and 67 GAPs have been identified in the human genome (Hall, 2012), with 30 GEFs and 20 GAPs thought to regulate Rho GTPases alone, including 22 GEFs and eight GAPs linked to Cdc42 in vertebrates (Table S2). GDIs have been less studied, and three RhoGDIs (RhoGDI 1 to RhoGDI 3) have been linked to Cdc42 localization (Hoffman et al., 2000; Lin et al., 2003).

\section{Mechanism of Cdc42-dependent polarity in yeast}

Polarized growth in the budding yeast Saccharomyces cerevisiae and division in the fission yeast $S$. pombe is controlled by Cdc 42 . In the budding yeast, germinating spores initiate polarized growth as a single cluster of Cdc42-GTP determines the nascent bud. Initially, multiple clusters of Cdc42-GTP can be detected at the membrane. However, competition for rapidly diffusing cytoplasmic factors between these initial clusters leads to the elimination of all but one (Bendezú et al., 2015; Goryachev and Pokhilko, 2008; Klünder et al., 2013; Slaughter et al., 2009; Woods and Lew, 2019) (Fig. 1).

Recent elegant optogenetic manipulation of this pathway has illustrated how an initial symmetry breaking event such as localizing of the Cdc42 GEF Cdc24 can trigger polarization (Witte et al., 2017). Once a cluster of Cdc42-GTP forms, it can be amplified through the recruitment of the cytosolic Cdc42 effector P21activated kinase (PAK) Cla4 (Bose et al., 2001), which can interact with Cdc24 and the adapter molecule Bem1 (Peterson et al., 1994). Recruitment of Cla4-Bem1-Cdc24 feeds into the activation of nearby Cdc42 molecules, thus growing the Cdc42-GTP cluster (Bendezú et al., 2015) (Fig. 1). This step of amplification is favored because Cdc42-GTP is more stable at the membrane than Cdc42GDP, which is maintained in the cytosol through its interaction with the RhoGDI Rdil (Hoffman et al., 2000).

During polarized growth, F-actin-dependent transport of Cdc42 (Wedlich-Soldner et al., 2003, 2004) also contributes to rapid recruitment and accumulation at the bud site. Interaction between $\mathrm{Cdc} 42$ and the exocyst component $\mathrm{Sec} 3$ promotes polarized secretion (Zhang et al., 2001, 2008). In addition, Cdc42-GTP interacts with the formin Bnilp (Evangelista et al., 1997) to promote the formation of F-actin tracks that are directed toward the bud and support vesicle trafficking (Evangelista et al., 2002; Pruyne et al., 2004; Sagot et al., 2002a). Therefore, in yeast, $\mathrm{Cdc} 42$ regulates polarized growth by coupling polarity at the membrane and cargo delivery.

\section{Polarization of the C. elegans embryo by localized inhibition of Cdc42}

Two developmental contexts in C. elegans are particularly relevant to this review: the one-cell embryo (zygote) (Fig. 2) and the fourto-six cell embryo, which undergoes radial polarization (Fig. 3).

\section{Cdc42 in the one-cell C. elegans embryo}

The $C$. elegans embryo establishes its antero-posterior (A-P) body axis before the first embryonic cleavage, which is asymmetric. This model system was used by Kenneth Kemphues and collaborators in the late 90 s to study the mechanisms of A-P polarity. Groundbreaking genetic screens identified the Partitioning-defective ( par) genes as being required to establish the antero-posterior axis of the cell (Kemphues et al., 1988; Watts et al., 1996). Later, the conserved serine/threonine atypical PKC-3 $[\mathrm{PKC} \zeta$ and $\mathrm{PKCl}$ in vertebrates (PKC $\zeta$, , hereafter) and aPKC in Drosophila] was added to this list of core regulators of A-P polarity (Tabuse et al., 1998). par genes encode adapter proteins (PAR-3, PAR-6 and PAR-5), serine/threonine kinases [PAR-1, PAR-4 (LKB1 in vertebrates, also known as STK11)] and PAR-2. In the zygote, A-P polarity is marked by the anterior segregation of the Par complex which consists of PAR-3, PAR-6 and PKC-3, and posterior accumulation of PAR-1 and PAR-2, which ultimately instruct asymmetric division through regulators of spindle position. The distribution of these proteins along the A-P axis depends on actomyosin flows and requires the reciprocal phosphorylation of PAR-1 by PKC-3 and PAR-3 phosphorylation by PAR-1 (Goehring and Grill, 2013; Motegi and Seydoux, 2013). Importantly, the relationship between Cdc42, PAR-6, PKC-3 and PAR-1, and the inhibition of PAR-3 [Bazooka (Baz) in Drosophila] by PAR-1 are both also part of the conserved signaling pathways that operate in epithelial cells to regulate polarized morphogenesis, (reviewed in Rodriguez-Boulan and Macara, 2014; St Johnston and Ahringer, 2010; Tepass, 2012).

In the zygote, PAR complex assembly allows for loading of PAR-6-PKC-3 onto the cortex and displacement of PAR-3-PAR-6PKC-3 toward the anterior pole of the cell through posterior-toanterior contractile flows of actomyosin (Goehring et al., 2011) (Fig. 2A). Cdc42 supports this process by promoting the stability of the PAR complex at the cortex, the recruitment of PAR-6-aPKC through direct binding to PAR-6, and by regulating actomyosin flow (Rodriguez et al., 2017; Wang et al., 2017). Importantly, the Cdc42-PAR-6-PKC-3 complex drives A-P polarity as PKC-3 phosphorylates the posterior PAR ( $\mathrm{pPAR}$ ) proteins PAR-1 and

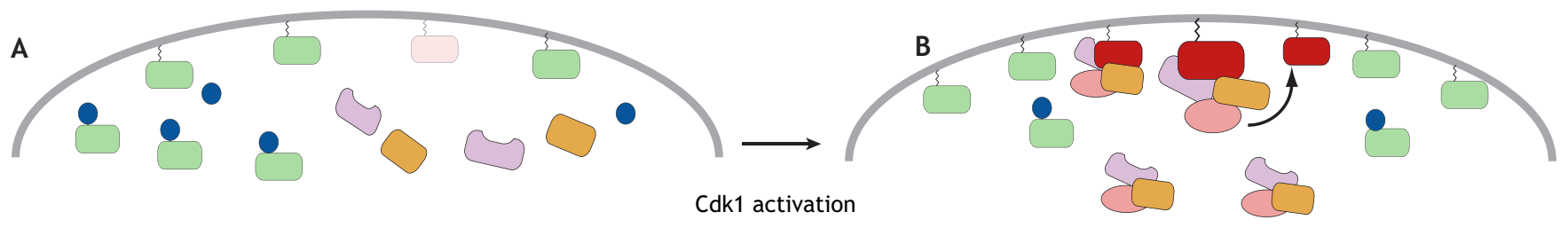

Key

Cdc42-GDP $\bigcirc$ Cdc42-GTP Cla4 $\bigcirc$ GDI $\longrightarrow$ Bem1 $\bigcirc$ Cdc24

Fig. 1. Mechanism of Cdc42-dependent polarity in budding yeast. Simplified mechanism of Cdc42 polarization of the budding yeast. (A) Prior to entry into $\mathrm{S}$ phase, no Cdc42 activation is detectable at the membrane. (B) During S phase, Cyclin dependent kinase 1 (Cdk1) is activated and promotes the binding

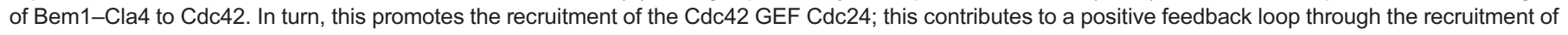
additional Cdc42 molecules. 
A

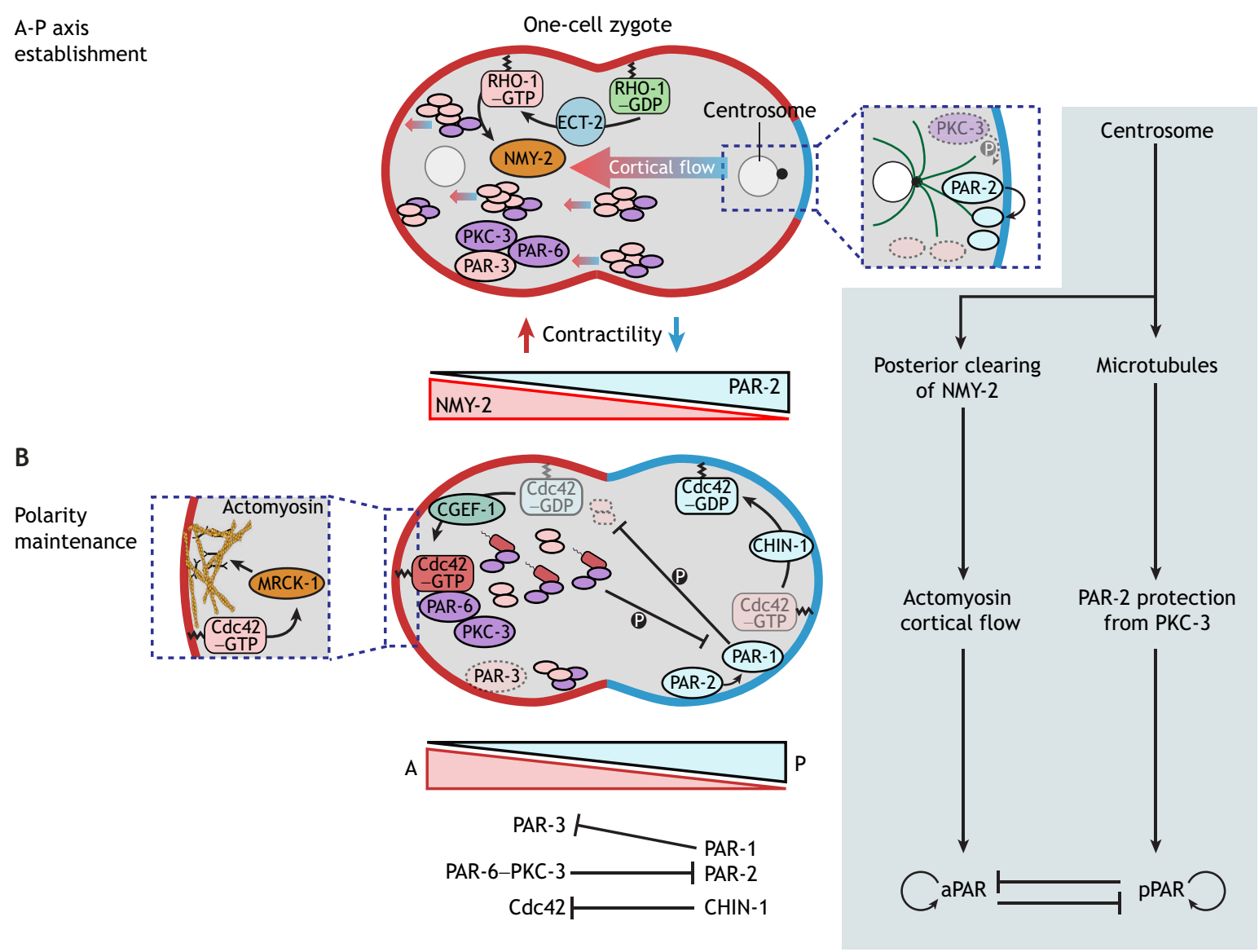

Fig. 2. Polarization of the $C$. elegans zygote. The $C$. elegans embryo establishes its antero-posterior (A-P) body axis before the first division, which is asymmetric. (A) In the early one-cell zygote, A-P axis establishment is achieved through activation of myosin II (NMY-2 in C. elegans) by active RHO-1, downstream of the GEF ECT-2. This results in cortical flow towards the anterior pole, which promotes anterior accumulation of the PAR complex (PAR-3PAR-6-PKC-3). At this stage PAR-2 is loaded onto the membrane at the posterior pole in microtubule-dependent manner (right inset). (B) In the later-stage zygote, polarity is maintained by spatially restricting the activity of Cdc42 to the anterior pole through the GEF CGEF-1 at the anterior pole and the localization of the GAP CHIN-1 at the posterior pole. At the anterior pole, the actomyosin cytoskeleton is regulated by MRCK-1, which acts downstream of Cdc42. Reciprocal antagonism between PAR-1 and PAR-3, and PKC-3 and PAR-1 promotes stable polarity.

PAR-2 to exclude them from the anterior pole of the cells (Aceto et al., 2006; Gotta et al., 2001; Kay and Hunter, 2001; Rodriguez et al., 2017). In addition, Cdc42 regulates actomyosin flow dynamics through PKC-3 (Cheeks et al., 2004; Munro et al., 2004) and, later on, the formation of an actomyosin cap at the anterior pole of the cell through myotonic dystrophy-related $\mathrm{Cdc} 42$ binding kinase 1 (MRCK-1) (Kumfer et al., 2010; Munro et al., 2004) (Fig. 2B). This regulation is conserved throughout evolution as MRCK $\beta$ [Genghis Khan (Gek) in Drosophila] regulates actomyosin at the apical pole of epithelial cells downstream of Cdc42 in mammalian cells and in Drosophila (Zihni et al., 2017).

As the zygote polarizes, active $\mathrm{Cdc} 42$ accumulates at the anterior pole of the cells, together with PAR-3, PAR-6 and PKC-3 (Kumfer et al., 2010). Anterior activation of $\mathrm{Cdc} 42$ results from the posterior accumulation of the RhoGAP Chimaerin homolog (CHIN-1), which inactivates Cdc42 (Beatty et al., 2013; Kumfer et al., 2010) (Fig. 2B). The RhoGEF CGEF-1 contributes to regulating the activation of $\mathrm{Cdc} 42$ and its cortical enrichment at the anterior pole of the cell (Kumfer et al., 2010). Therefore, whereas in yeast the localized recruitment of the Cdc42 GEF activates Cdc42 at the incipient bud site, in the C. elegans zygote, the localization of a GAP plays an important role in spatially regulating where $\mathrm{Cdc} 42$ is active.

\section{Spatial regulation of $\mathrm{Cdc42}$ during radial polarity}

In the $C$. elegans blastoderm, radial polarization is regulated by $\mathrm{Cdc} 42$, which is activated at the junction-free, outward-facing membranes (Anderson et al., 2008). This is because the Cdc42 GAP PAC-1 is recruited at the lateral membrane that mediates cell-cell junction (Fig. 3). In these cells, activation of Cdc42 at the junction-free membrane drives the selective accumulation of PAR-6-PKC-3 (Marston et al., 2016; Rohrschneider and Nance, 2009). Cell junctions are mediated by the main adherens junction protein E-cadherin homologue HMR-1 and associated catenins HMP-1, HMP-2 and the p120 homolog JAC-1 (Klompstra et al., 2015). Radial symmetry is first established as HMR-1 engages in trans to promote lateral junctions between embryonic cells. Formation of lateral junctions then leads to the recruitment of PAC-1 via the linker protein PICC-1, which binds to JAC-1 (Klompstra et al., 2015). As PAC-1 is recruited to the lateral junction, $\mathrm{Cdc} 42$ is thus inactivated. Simultaneously, at the junction-free membrane, active GTP-loaded Cdc42 becomes enriched. Here, Cdc42 activity is promoted by two GEFs, ECT-2 and CGEF-1, which function redundantly (Chan and Nance, 2013). As is the case in the zygote, in the blastoderm Cdc42-GTP promotes the localized recruitment of PAR-6-PKC-3 and MRCK-1, and their activation to regulate actomyosin, which 


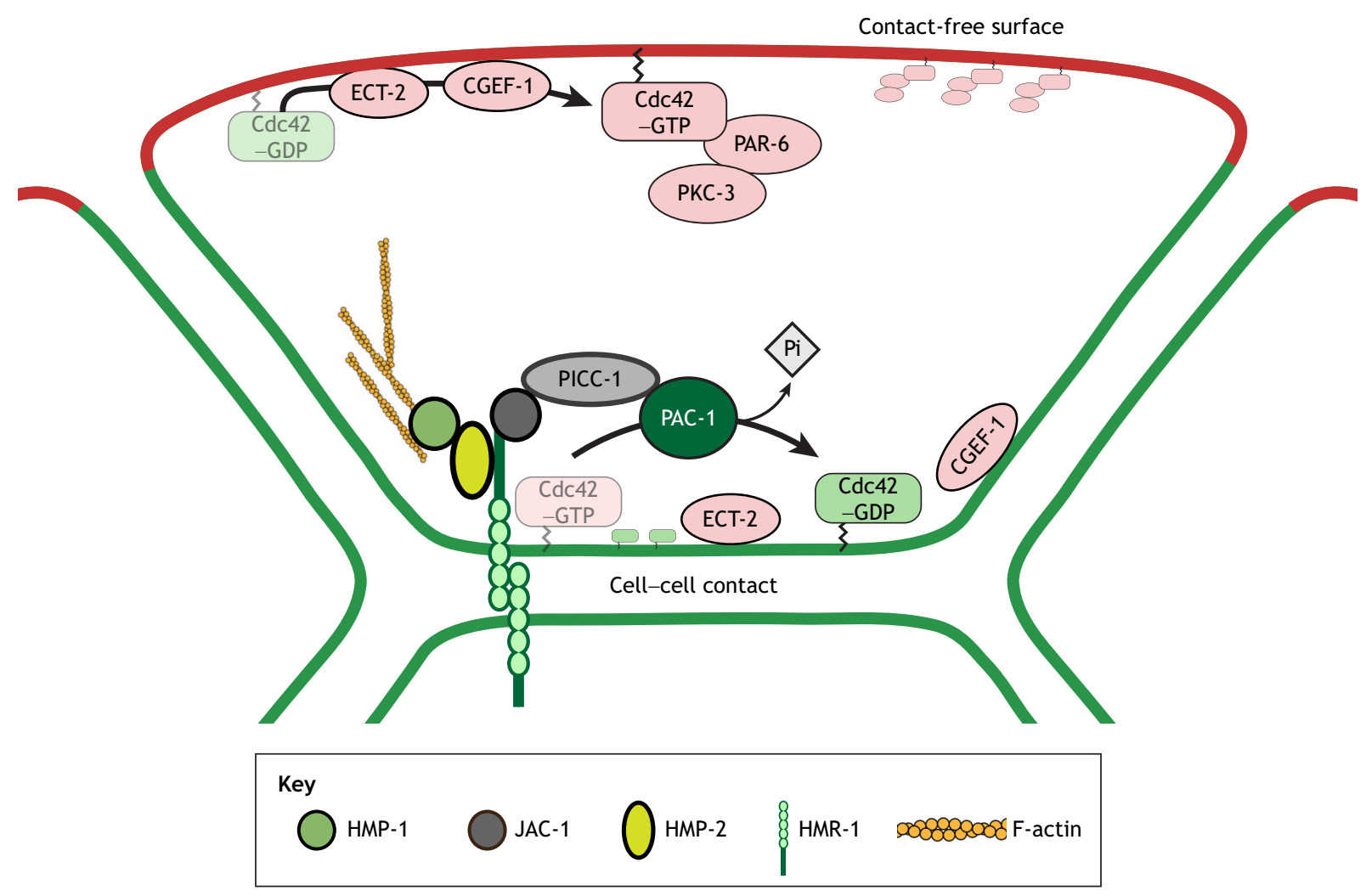

Fig. 3. Cdc42 regulates polarization of the $C$. elegans blastocyte. Cell-cell contacts containing HMR-1 are shown outlined in green and junction-free, outward facing membranes in red. PAC-1 is recruited to the junction through PICC-1, leading to the conversion of Cdc42-GTP into Cdc42-GDP. At the junction-free membrane, ECT-2 and CGEF-1 promote the accumulation of Cdc42-GTP and the associated recruitment of the PAR-6-PKC-3 complex. The polarized distribution of Cdc42-PAR-6-PKC-3 and PAR-3 is required for cell morphogenesis during gastrulation.

promotes cell constriction and internalization during gastrulation (Harrell and Goldstein, 2011).

\section{Role of Cdc42 in epithelial cell types}

Our knowledge of the mechanisms of epithelial morphogenesis is mostly based on genetic approaches in relatively simple model organisms such as Drosophila melanogaster, and cultured mammalian cells. While there are some differences in the topology of vertebrate cells compared to invertebrate cells, and the mechanisms of polarity establishment, many of the molecular factors that regulate epithelial polarity in invertebrates are conserved in mammals.

\section{Epithelial cell polarity}

Epithelial cells can adopt various shapes from flat, or squamous, to tall, or columnar. They can assemble into sheets that can be stratified. They are polarized along the apical (top)-basal (bottom) axis, and this polarity is readily visible at their plasma membrane (Fig. 4A). Typically, the apical membrane faces the luminal space or external milieu and consists of tightly packed microvilli, which contain bundled F-actin. The apical membrane may present a non-motile primary cilium, which is a microtubule-based organelle that acts as a signaling hub (Malicki and Johnson, 2017). Motile cilia may also be present at the apical surface of the cell, where they can promote mucus clearance, as for example in the lung (Mitchison and Valente, 2017). Discrete lateral domains that mediate cell-cell adhesion and can act as paracellular diffusion barriers are found along the lateral surface. The basal domain is in contact with the extracellular matrix (ECM). This polarized regionalization underpins tissue morphogenesis as it allows these cells to assemble into sheets that function as diffusion barriers (Tyler, 2003).

A shared feature between all epithelial cell types is the presence of a cell-cell junction at the apical-lateral border of the plasma membrane. In vertebrates, this junction is the paracellular junction and is called the tight junction. It contains transmembrane molecules that engage in trans to seal the epithelium (Fig. 4B). These include occludins, claudins and junctional adhesion molecule A (JAM-A, also known as F11R), which are linked to the cytoskeleton through proteins such as the adaptor proteins zonula occludens (ZO)1, ZO2 and ZO3 (also known as TJP1-TJP3 in vertebrates), and cingulin (Ebnet et al., 2004; Matter and Balda, 2003; Tsukita et al., 2001). Basal to the tight junctions are the adherens junctions, which mediate cell-cell adhesion and signaling (Harris and Tepass, 2010b), and contain E-cadherin (Ecad hereafter) and nectin family proteins. Interaction between Ecad molecules in trans promotes intercellular adhesion and coupling to the actomyosin cytoskeleton through the catenin adapter proteins $\alpha$-catenin and $\beta$-catenin (Lecuit and Yap, 2015; Steinbacher and Ebnet, 2018). In addition, some tissues have desmosomes, which contain cadherin-like proteins that are linked to keratin intermediate filaments to form spot-like junctions at the lateral membrane. These contribute to the promotion of mechanical resilience in epithelia (Garrod and Chidgey, 2008). Finally, GAP junctions consist of connexin molecules that assemble into hemichannels and directly connect the cytosol of two neighboring cells to allow the exchange of molecules and ions (Dermietzel et al., 1990). 
A

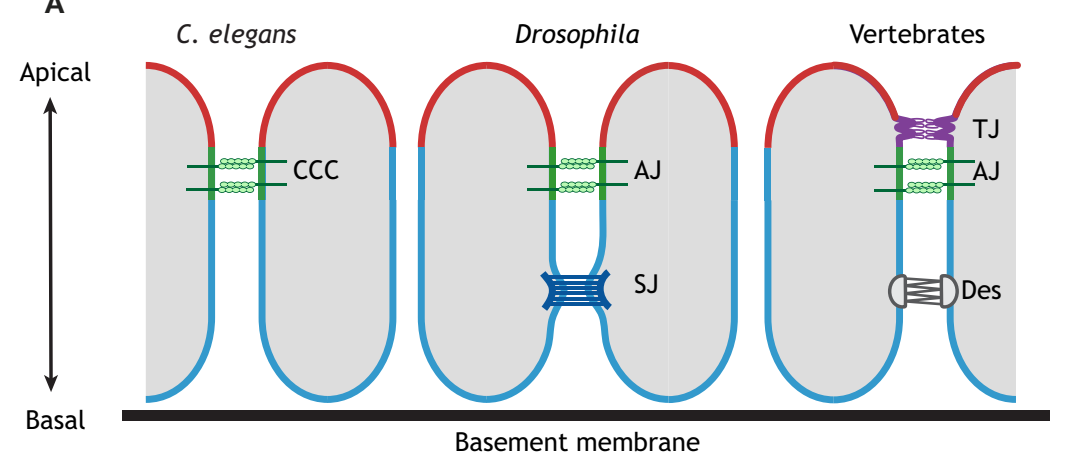

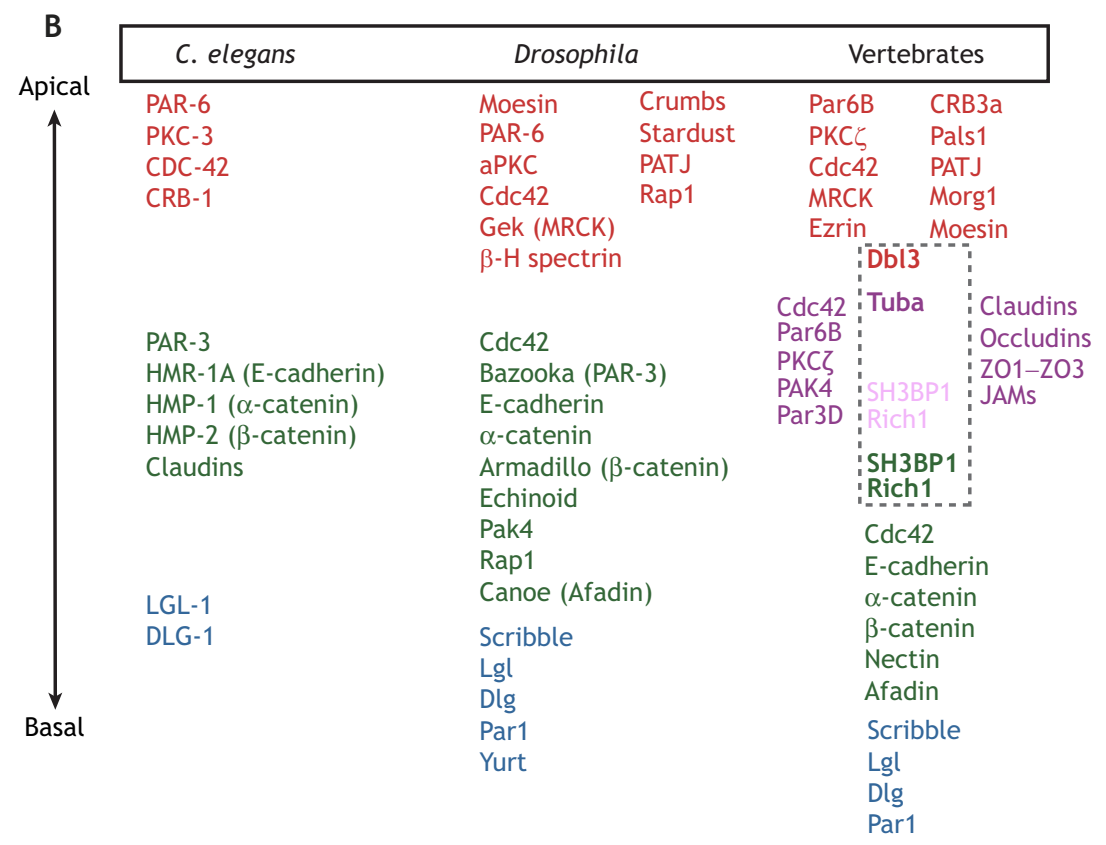

C

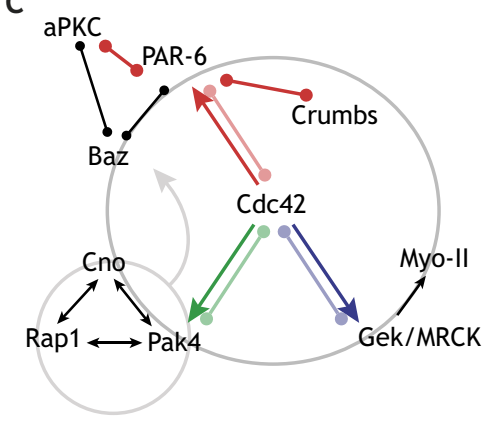

Fig. 4. Epithelial cell junctions and principal regulators of epithelial morphogenesis. (A) Schematic representation of typical epithelial cells in $C$. elegans, Drosophila and vertebrates. CCC, cadherin-catenin complex; AJ, adherens junction; SJ, septate junction; TJ, tight junction; Des, desmosomes. Apical and contiguous sub-apical membranes are outlined in red, lateral and basal membranes in blue. AJ and CCC are in green, and TJ in purple. (B) Overview of the principle proteins that have been shown to regulate apical-basal polarity and/or morphogenesis in these three model systems. Color coding as in panel A. (C) Schematic representation of the network of apical proteins that orchestrate apical membrane and apical-lateral junction morphogenesis in Drosophila (and, in particular, in the pupal photoreceptor) and vertebrate cells. Arrows indicate activation and connector lines protein interactions. Color coding as in panel A.

The configuration of epithelial cells in invertebrates is similar but not identical to that found in vertebrates (Knust and Bossinger, 2002; Tepass et al., 2001) (Fig. 4A). In Drosophila the apical-lateral junction is the adherens junction. The paracellular junction, and equivalent of the tight junction, is called the septate junction. An exception to this organization is found in the Drosophila mid-gut, where the septate junction is the apical-lateral junction, and is found apical to the adherens junction (Chen et al., 2018). In C. elegans, the apical-lateral junction is called the cadherin-catenin complex (CCC) and is composed of HMR-1A (Ecad), HMP-1 and HMP-2 (catenins) and claudins (Labouesse, 2006) (Fig. 4A,B). Another adhesion complex, consisting of DLG1 and AJM-1 is found immediately basal to the CCC and has been proposed to serve as paracellular barrier (Asano et al., 2003).

\section{Epithelial polarity protein networks}

Drosophila and C. elegans genetics have been instrumental in identifying genes that regulate cell polarity and epithelial morphogenesis (Fig. 4B,C). In addition, biochemical evidence shows that the apical proteins can assemble into canonical complexes that are conserved through evolution. These complexes include the PAR complex and the Crumbs complex (CrumbsPALS1-PATJ) (Bulgakova and Knust, 2009; Tepass, 2012). However, these complexes are interlinked because PAR-6 can bind to Crumbs (CRB3 in vertebrates) and Stardust (PALS1 in vertebrates, also known as MPP5) (Hurd et al., 2003; Kempkens et al., 2006; Lemmers et al., 2004; Wang et al., 2004), and Stardust to Bazooka (Drosophila homologue of PAR-3) (Krahn et al., 2010). Therefore, the interactions between Crumbs, Stardust/PALS1, PAR-6 and Bazooka/PAR-3 are likely to be dynamic (Fig. 4C). Importantly, Cdc42 regulates how these proteins interact with each other during epithelial morphogenesis. For instance, in Drosophila, $\mathrm{Cdc} 42$ is required for recruitment of Bazooka and PAR-6-aPKC to the plasma membrane and for the apical recruitment of PAR-6aPKC and Crumbs. This is in part because Cdc42 binding to PAR-6 promotes the binding of PAR-6 to Crumbs (Nunes de Almeida et al., 2019 preprint; Walther and Pichaud, 2010). Presumably, Cdc42 binding to PAR-6 promotes a conformational rearrangement that potentiates the affinity of PAR-6 for binding to Crumbs (Peterson et al., 2004; Whitney et al., 2011). Via this mechanism, 
Cdc42 coordinates the association of Bazooka, PAR-6 and aPKC, and Crumbs recruitment to promote apical membrane and adherens junction morphogenesis. Similar to Drosophila, in vertebrate cells such as Madin-Darby canine kidney cells (MDCK), Cdc42 regulates the localization of PAR-6- $\mathrm{PKCl}$ (Martin-Belmonte et al., 2007). In Drosophila, the interaction between PAR-6aPKC and Crumbs promotes the separation of the apical membrane and adherens junction. Crumbs binding to PAR-6 is thought to outcompete PAR-6 binding to Bazooka, leading to the exclusion of Bazooka from the PAR complex (Walther and Pichaud, 2010; Morais-de-Sá et al., 2010; Nunes de Almeida et al., 2019 preprint). Bazooka exclusion also requires Bazooka phosphorylation by aPKC at a conserved serine (S980 in flies; S827 in PAR-3) (Krahn et al., 2010; Morais-de-Sá et al., 2010; Walther and Pichaud, 2010; Hirose et al., 2002). Bazooka exclusion from the PAR complex leads to its localization to the apical-lateral boundary, where it is thought to promote adherens junction morphogenesis. Similarly, in vertebrate cells, PAR-3 localizes at the tight junction, basal to CRB3, PALS1 and PAR-6. Although it is not clear where the interactions between Crumbs/CRB3, Stardust/PALS1, PAR-6aPKC and Bazooka/PAR-3 take place in cells, one possibility is that they occur where these proteins co-localize, i.e. at the apical tip of the tight junction (Zihni et al., 2014) in vertebrate cells and the apical region of the adherens junction in fly cells (Walther et al., 2016; Walther and Pichaud, 2010).

\section{Cdc42 regulates epithelial morphogenesis}

Epithelial cell culture models have provided important insights into the potential mechanisms of junction maturation during epithelial morphogenesis. In 2D epithelial monolayers where cell-cell junctions have been disrupted, either through calcium depletion or scratch assays, and then allowed to reform (Gumbiner and Simons, 1986; Todaro et al., 1965), Ecad-rich spot-like junctions, also referred to as primordial junctions, form as filopodia-like extensions make contact between neighboring cells (Fig. 5A,B). In MDCK cells, the formation and maturation of these spot-like junctions, which also contain the tight junction proteins ZO1 and JAM-A, is regulated by Rac, Rho and Cdc42 (Coopman and Djiane, 2016) (Fig. 5B). Junction maturation in 2D cultures requires $\mathrm{Cdc} 42$ and its effectors PAR-6B-PKC $\zeta, \mathrm{l}$, and P21-activated kinase 4 (PAK4) (Jin et al., 2015; Wallace et al., 2010) (Fig. 5C).

\section{Role of the Cdc42-PAR-6-aPKC axis}

Cdc42 binding to PAR- 6 is thought to regulate the localization of PKC, ,l. Three PAR-6 proteins have been characterized in mammals: PAR-6A, PAR-6B and PAR-6C (also known as PARD6A, PARD6B and PARD6C, respectively) (Gao and Macara, 2004; Noda et al., 2001), and one PAR-6 protein in Drosophila (Petronczki and Knoblich, 2001). A feature common to all PAR-6 proteins is the presence of a pseudo-CRIB domain juxtaposed to a PDZ domain, both of which contribute to supporting the binding of Cdc42 (Garrard et al., 2003; Joberty et al., 2000; Ranganathan and Ross, 1997). In addition, the N-terminus of PAR-6 binds to aPKC/PKC $\zeta, 1$ (Joberty et al., 2000; Lin et al., 2000; Suzuki et al., 2001). PAR-6A, PAR-6B and PAR-6C can all localize to the tight junction (Durgan et al., 2011; Gao and Macara, 2004), while PAR-6B also localizes to the apical membrane (Hayase et al., 2013) in MDCK cells. In 2D cultures of human bronchial 16HBE cells, decreasing the levels of $\mathrm{Cdc} 42$, PAR-6B or PKC $\zeta$, , stalls junction maturation, as only spot-like junctions can be detected in

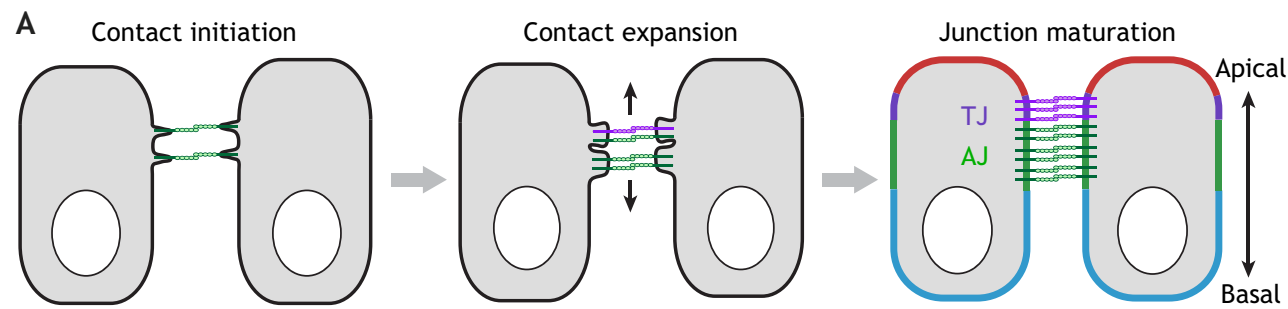

B Contact initiation

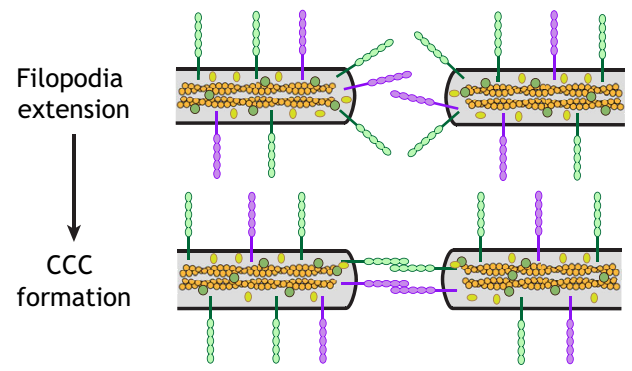

C Junction maturation

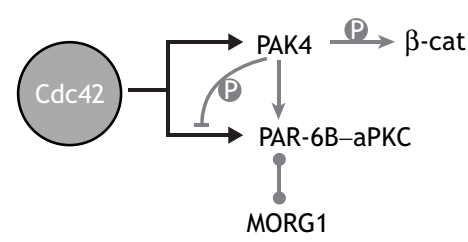

Key

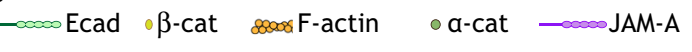

Fig. 5. Cdc42 regulation during epithelial morphogenesis. (A) Schematic representation of how junctions mature during epithelial morphogenesis in epithelia monolayers (such as MDCK and Caco-2 cells). (B) Initial junctional contacts consist of spot junctions mediated by filopodia that extend between cells. These filopodia present adhesion molecules, including Ecad, nectins and JAM-A. As intercellular contacts are made, a cadherin- $\beta$-catenin- $\alpha$-catenin complex assembles (CCC). PAR-3 and associated PAR-6B-PKC $\zeta, 1$ can be recruited through JAM-A. (C) Following initial spot junction formation, TJ and AJ mature; this is regulated by Cdc42 through PAK4 and PAR-6-aPKC. In vertebrate cells, junction maturation depends on PAK4-mediated phosphorylation of PAR-6B, which excludes it from the AJ and instead favors its localization at the TJ and apical membrane through interacting with MORG1. Junction maturation also depends on PAK4-mediated phosphorylation of $\beta$-catenin, which stabilizes Ecad. 
these cells (Jin et al., 2015; Wallace et al., 2010). Similarly, inhibiting Cdc42 in 2D cultures of Caco-2 and MDCK cells interferes with adherens junction assembly (Fukuhara et al., 2003; Otani et al., 2006). In addition, manipulation of Cdc42 using dominant-negative or constitutively active transgenes shows that it regulates endocytosis at the apical membrane of MDCK cells, as well as delivery of basolateral cargoes (reviewed in Harris and Tepass, 2010a). Further evidence that $\mathrm{Cdc} 42$ regulates apical endocytosis in vivo is found in Drosophila tissues and in the salivary gland in mice (Georgiou et al., 2008; Harris and Tepass, 2008; Leibfried et al., 2008; Shitara et al., 2019).

How exactly the Cdc42-PAR-6-aPKC complex promotes epithelial morphogenesis is not fully understood. The PAR-6aPKC complex contributes to the maintenance of epithelial polarity by phosphorylating L(2)gl and PAR-1, which leads to their dissociation from the plasma membrane (Benton and St Johnston, 2003; Böhm et al., 1997; Hurov et al., 2004; Hutterer et al., 2004; Plant et al., 2003; Suzuki et al., 2004). In addition, findings for Drosophila and mammalian epithelial cells, combined with biochemical studies, indicate that the functions of PAR-6-aPKC during this process include suppressing the contractility of the actomyosin cytoskeleton (Ishiuchi and Takeichi, 2011; Röper, 2012), promoting Ecad endocytosis (Georgiou et al., 2008; Leibfried et al., 2008), and stabilizing Crumbs at the plasma membrane to maintain the integrity of the apical-lateral junction (Harris and Tepass, 2008). Furthermore, in vertebrate cells, PKC $\zeta, 1$ phosphorylation of the tight junction components JAM-A, claudin-4 and occludin, (D'Souza et al., 2007; Iden et al., 2012; Jain et al., 2011) promotes junctional integrity.

\section{The Cdc42-PAK4 axis in junction maturation}

As noted above, the Cdc42 effector PAK4 [Mushroom bodies tiny (Mbt) in Drosophila] is also required to promote junction maturation, both in Drosophila and vertebrates (Jin et al., 2015; Schneeberger and Raabe, 2003; Selamat et al., 2015; Wallace et al., 2010; Walther et al., 2016) (Fig. 5C). PAK4 belongs to the Type II PAK family, which comprises PAK4, PAK5 and PAK6 (Bokoch, 2003). Broadly, PAK kinases are required for the regulation of cytoskeletal dynamics, as well as for the localization or turnover of adherens junction components at the plasma membrane (Pirraglia et al., 2010; Tay et al., 2010; Walther et al., 2016). Binding of Cdc42-GTP to the CRIB domain of PAK4 is thought to only marginally increase their kinase activity; however, it has been shown to regulate their localization. For instance, binding of Cdc42 to Mbt/PAK4 localizes it to developing adherens junctions in human cells (Wallace et al., 2010), zebrafish (Selamat et al., 2015) and Drosophila epithelial cells (Schneeberger and Raabe, 2003). PAK4 can also promote F-actin morphogenesis through activating LIMK and the actin-severing protein cofilin (Twinstar in Drosophila) (reviewed in Rane and Minden, 2014). This could also stimulate junction maturation and apical membrane morphogenesis. Interestingly, in human cells, PAK4 phosphorylates PAR-6B, which promotes its binding to MORG1 and facilitates the recruitment of PAR-6B-aPKC through CRB3 (Hayase et al., 2013; Jin et al., 2015) (Fig. 5C). Phosphorylation of PAR-6 by Mbt is not conserved in flies (Walther et al., 2016); however, there is evidence that $\mathrm{Mbt}$ regulates junction maturation by phosphorylating Armadillo (Arm; the fly homolog of $\beta$-catenin) and that this regulation is conserved across different species (Menzel et al., 2008; Selamat et al., 2015). In the pupal fly photoreceptor, Mbt-mediated phosphorylation of Arm stabilizes adherens junction components including Bazooka at cell-cell contacts. Retention of Bazooka at the adherens junction plays a role in preventing the ectopic localization of the PAR complex and Ecad at the lateral membrane (Walther et al., 2016). Although the mechanisms underlying Mbt/PAK4 function during junction maturation are not fully understood, recent work in Drosophila has linked Mbt function during adherens junction maturation to that of the small GTPase Rap1 and its effector Canoe (Cno; afadin in humans), which binds to F-actin (Walther et al., 2018). The Rap1-Cno pathway also regulates Bazooka localization in the fly embryo during cellularization (Bonello et al., 2018), and Ecad trafficking in MDCK cells (Hogan et al., 2004).

\section{Cdc42 GEFs and GAPs during epithelial morphogenesis}

The spatial regulation of $\mathrm{Cdc} 42$ has been shown to be essential for the regulation of junction formation and maintenance. A key regulator of Cdc42 in epithelial cells is its GAP SH3BP1, which has been shown to promote junction assembly in $2 \mathrm{D}$ cultures of Caco-2 cells and in 3D spheroids (Elbediwy et al., 2012). SH3BP1 forms a complex with the ZO1 binding partner paracingulin (CGNL1) and the scaffold protein $\mathrm{CD} 2 \mathrm{AP}$, a protein that has been shown to regulate F-actin dynamics and endocytosis (Gauthier et al., 2007; Tang and Brieher, 2013). Further, SH3BP1 colocalizes with occludin and $\beta$-catenin, and is thus found at both tight junctions and adherens junctions. In human intestinal Caco-2 cells, SH3BP1 is required to limit Cdc42 activity in order to promote assembly of the peri-junctional actin belt that stabilizes the adherens junctions and promotes tight junction formation (Elbediwy et al., 2012). Therefore, junction maturation requires limitation of $\mathrm{Cdc} 42$ activity at the junctions. Similarly, in MDCK cells, the Cdc42 GAP Rich1 (also known as ARHGAP17), which is related to $\mathrm{SH} 3 \mathrm{BP} 1$, is required for the maturation and maintenance of tight junctions (Wells et al., 2006). In these cells, Rich1 is enriched at the basal part of the tight junctions and at the apical region of adherens junctions (Wells et al., 2006). Binding of Rich1 to Amot, a protein that is found both at tight junctions and adherens junctions, is thought to regulate Rich1 localization to these junctions (Wells et al., 2006). The function of Rich1 in maintaining tight junction integrity has been in part linked to the Rich1-Amot module, which regulates the turnover of tight junction components (Wells et al., 2006). Localization of SH3BP1 and Rich1 bears similarities to that of PAC1 in the C. elegans embryo, which raises the possibility that preventing Cdc42 activity at the developing cell-cell junctions is required for junction maturation. Further, the RhoA-Rok pathway promotes adherens junction morphogenesis and can be inhibited by $\mathrm{Cdc} 42$ through aPKC phosphorylation of Rok in Drosophila (Röper, 2012) and ROCK1 in MDCK cells (Ishiuchi and Takeichi, 2011). It is therefore conceivable that $\mathrm{Cdc} 42$ activity needs to be limited at the developing adherens junction as part of a mechanism that controls the balance between the RhoA-Rok and Cdc42-PAR-6-aPKC pathways.

Next to SH3BP1 and Rich1, the Cdc42 GEF Tuba has been found to localize at the apical tip of the tight junction in 2D cultures of Caco-2 cells. In these cells, Tuba has been shown to be required for the normal maturation of adherens junctions, and for their maintenance (Otani et al., 2006). At least part of the function of $\mathrm{Cdc} 42$ during these processes was attributed to the $\mathrm{Cdc} 42$ effector $\mathrm{N}-\mathrm{WASp}$, and thus branched F-actin morphogenesis. Therefore, it is likely that Tuba-mediated activation of Cdc42 leads to the activation of both the N-WASp and PAR-6-aPKC pathways. How exactly Cdc42-GTP might distribute between N-WASp and PAR-6-aPKC is not well understood. One possibility is that clusters of $\mathrm{Cdc} 42-$ PAR-6-PKC $\zeta, 1$ exist in close vicinity to $\mathrm{Cdc} 42-\mathrm{N}-\mathrm{WASp}$ clusters. In addition, a recent study in MDCK cells has shown that the RhoGEF 
FARP2 also regulates Cdc42 function during tight junction assembly (Elbediwy et al., 2019). However, how FARP2 function relates to that of Tuba during epithelial morphogenesis is not clear.

\section{Role of $\mathrm{Cdc42}$ in regulating lumen formation}

3D cultures of epithelial cells (Griffith and Swartz, 2006; Yamada and Cukierman, 2007) have been instrumental in elucidating the mechanisms of epithelial morphogenesis, and in particular luminogenesis (Fig. 6). In MDCK spheroids, apical recruitment of $\mathrm{Cdc} 42$ has been proposed to depend on annexin 2 and the lipid phosphatase PTEN, which prevents accumulation of phosphatidylinositide-3,4,5-triphosphate (PIP3) at the apical pole of the cells (Martin-Belmonte et al., 2007). However, Cdc42 localization is not limited to the apical membrane, and it is not well understood where Cdc42 is activated in these cells (Martin-Belmonte et al., 2007). Similarly, in the Drosophila photoreceptor, PTEN at the adherens junctions limits levels of PIP3 at the apical membrane, which also contains PIP2 (Pinal et al., 2006) and Cdc42-GTP (Nunes de Almeida et al., 2019 preprint). Regulation of PIP2 and PIP3 levels along the apical-basal axis of epithelial cells is therefore conserved through evolution. In 3D MDCK spheroids, apical activation of Cdc42 appears to depend on the coincidence between PIP2 at the membrane and the presence of Tuba in the apical cytosol.

In addition to regulating trafficking and phosphorylating junctional proteins, the $\mathrm{Cdc} 42-\mathrm{PAR}-6 \mathrm{~B}-\mathrm{PKC} \zeta$ axis also regulates luminogenesis through spindle regulation (Bryant et al., 2010; Jaffe et al., 2008). In 3D MDCK spheroids, apical-basal polarity is already apparent at the two-cell stage as the initial founder cell divides (Fig. 6A). During cell division, the placement of the cleavage furrow is linked to the orientation of the spindle, which depends on Cdc42. The cleavage furrow determines the formation of the midbody during cell division, which, in turn, determines apical identity (Jaffe et al., 2008; Mitsushima et al., 2009; Qin et al., 2010; Rodriguez-Fraticelli et al., 2010). During this process, the transmembrane phosphoglycoprotein podocalyxin, which is localized all around the founder cell, is transcytosed toward the apical membrane initiation site (AMIS), which forms at the midbody and is marked by PAR-3 and components of the exocyst (Bryant et al., 2010; Li et al., 2014; Willenborg et al., 2011). Transcytosis of podocalyxin appears to be particularly important to establish the apical-basal axis and requires the presence of Rab35 (Klinkert et al., 2016; Mrozowska and Fukuda, 2016). Concomitantly, the tight
A

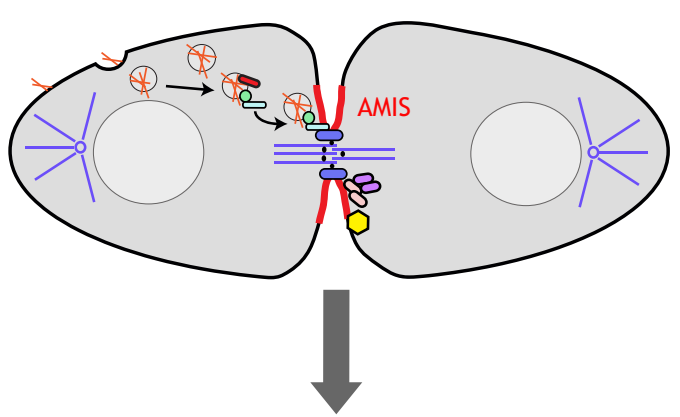

B

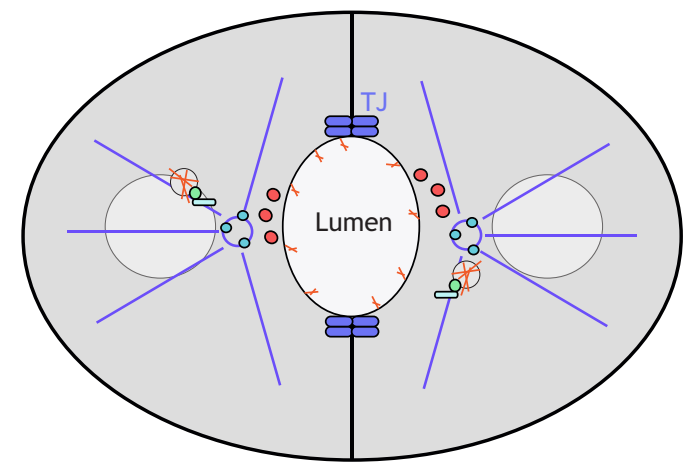

C

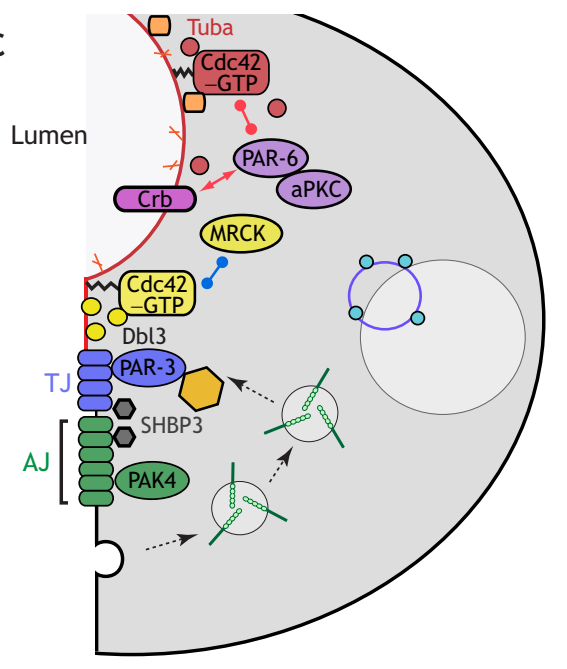

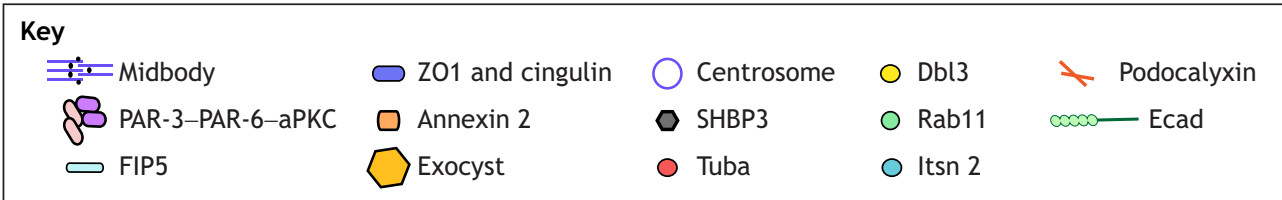

Fig. 6. Epithelial morphogenesis in vertebrate cells in 3D. Illustrated steps of luminogenesis in 3D culture. (A) The midbody serves as a landmark where ZO1 and cingulin mark the apical membrane initiation site (AMIS). The AMIS instructs further steps of lumen formation, including apical cargo delivery. Delivery of apical cargos, including podocalyxin, which is trancytosed from the basal membrane, is directed toward the AMIS. The endocytic pathway promotes the delivery of apical cargo, including Rab11 and FIP5. FIP5 binds to cingulin to promote vesicle docking. (B) As a central lumen forms, the tight junction begins to differentiate laterally to the apical membrane. (C) Activation of Cdc42 at the apical membrane arises from the coincidence of annexin 2-dependent recruitment and immobilization by activation through Tuba proteins. Tuba is found in the cytosol in the vicinity of the apical cortex, while intersectin-2 (Itsn2) is localized at the centrosome. Dbl3 is localized at the TJ to regulate microvilli morphogenesis through MRCK. PAR-3 is localized at the TJ, where it serves as a receptor for the exocyst, which regulates the transcytosis of Ecad to ensure AJ integrity. 
junction protein cingulin is recruited to the AMIS, where it interacts with FIP5 (also known as RAB11FIP5) to promote cargo delivery by the Rab8a-Rab11a pathway (Fig. 6B) (Mangan et al., 2016). In addition, Cdc42 ensures that during cell division, the spindle is aligned perpendicular to the plane of the junctions (Jaffe et al., 2008). This regulation during mitosis also depends on aPKC and ensures that only a single central lumen is formed.

In addition to Tuba, another Cdc42 GEF, intersectin-2 (Itsn2), regulates lumen formation (Fig. 6A,B) (Qin et al., 2010; RodriguezFraticelli et al., 2010). Like Tuba, intersectin-2 regulates spindle positioning during mitosis. In Caco-2 cells, intersectin- 2 accumulates at the centrosome and around the edge of the spindle poles, suggesting that it regulates $\mathrm{Cdc} 42$ activity in the vicinity of these locations (RodriguezFraticelli et al., 2010). At the spindle pole, intersectin-2 might promote Cdc42-dependent interaction between the astral spindle and the cell cortex. Conversely, Tuba, which localize to the tight junctions in Caco-2 cells and the cytoplasm in vicinity of the apical membrane in $3 \mathrm{D}$ MDCK spheroids (Otani et al., 2006; Qin et al., 2010; RodriguezFraticelli et al., 2010), is thought to contribute to spindle alignment by preventing the spindle pole from interacting with the apical cortex. The effectors of Cdc42 function at the centrosome remain to be identified, but might include factors, such as PAK2 (Mitsushima et al., 2009) or the formin diaphanous 3 (Yasuda et al., 2004), which have been linked to $\mathrm{Cdc} 42$ and are known to regulate spindle orientation.

While Cdc42 likely regulates apical cargo delivery (Musch et al., 2001) and the endocytic pathway (Harris and Tepass, 2008), its apical activation depends on the apical trafficking pathway. This relationship between $\mathrm{Cdc} 42$ and apical cargo delivery is well supported by the finding that in 3D MDCK spheroids, Rab11-dependent delivery of apical proteins is required for normal Cdc42 activation (Bryant et al., 2010). Furthermore, reminiscent of the mechanism of Cdc 42 polarity in budding yeast, recent work in the Caco-2-derived LS174T-W4 cell line using FRAP experiments has shown that activation of $\mathrm{Cdc} 42$ by Tuba leads to a threefold increase in the immobilization of $\mathrm{Cdc} 42$ to the apical membrane (Bruurs et al., 2017). This promotes Cdc42 clustering and presumably enables a reaction-diffusion mechanism that is comparable to that operating in budding yeast to determine polarity. In epithelial cells, this mechanism might contribute to ensuring that only one apical site is specified. In addition, there is evidence that in both vertebrate and invertebrate epithelial cells, Cdc42 is present on trafficking vesicles (Harris and Tepass, 2008; Bryant et al., 2010; Willenborg et al., 2011). It is therefore possible that in epithelial cells, Cdc42 is activated by Tuba in the vicinity of the apical membrane. This would promote the accumulation of Cdc42-GTP at the apical membrane that bears annexin 2, and coincide with the delivery of cargos such as CRB3 (Bryant et al., 2010; Willenborg et al., 2011). In this model, PAR-3, which localizes at the AMIS, might serve as a marker for the targeted delivery of apical cargos. A role for PAR-3 in facilitating the delivery of apical cargo, including that of Ecad, is supported by the finding that PAR-3 can interact with Exo70 (also known as EXOC7), a component of the exocyst, which mediates secretory vesicle docking at the plasma membrane (Fig. 6C) (Ahmed and Macara, 2017).

\section{Cdc42 promotes apical membrane morphogenesis through Gek/MRCK}

In addition to regulating luminogenesis and junction integrity, Cdc42 also promotes apical membrane morphogenesis. Work in Caco-2 cells has shown that this function is linked to the actomyosin cytoskeleton and the Cdc42 GEF Dbl3 (Zihni et al., 2014). In these cells, Dbl3 is recruited to the apical membrane in part through binding to Ezrin, which cross-links the actomyosin cytoskeleton to the plasma membrane. A main effect downstream of the Dbl3Cdc42 pathway is the activation of MRCK $\beta$ (Gek in Drosophila), which regulates the actomyosin cytoskeleton through activation of myosin II (Zihni et al., 2017). Therefore, Cdc42 coordinates the morphogenesis of sub-apical membranes and microvilli through PAR-6-aPKC/PKC $\zeta, l$ and MRCK (Zihni et al., 2014, 2017). The architecture of this protein network is very similar to that operating in the C. elegans zygote (Fig. 2), which supports the anterior recruitment of PAR-6-PKC-3 and regulates the actomyosin cytoskeleton through MRCK-1. These similarities suggest that coupling of anterior recruitment and cytoskeletal regulation is a conserved feature of the mechanisms through which $\mathrm{Cdc} 42$ regulates cell polarity. How Cdc42 distributes between MRCK $\beta /$ Gek and PAR-6-aPKC is not clear, and one possibility is that this distribution depends on the GEF that is associated with $\mathrm{Cdc} 42$ during epithelial cell morphogenesis.

\section{Conclusion and perspectives}

Cdc42 plays an essential role during cell polarity establishment in yeast and animal cells. At the core of this role is its local activation or inactivation by GEFs and GAPs, and its links to the regulation of actomyosin, membrane delivery and endocytosis. Several GEFs and GAPs have been shown to regulate $\mathrm{Cdc} 42$ to promote epithelial morphogenesis in vertebrate epithelial cells. However, it is unclear where exactly $\mathrm{Cdc} 42$ is activated or inactivated in these cells. It is also unclear how $\mathrm{Cdc} 42$ distributes between the different GEFs involved, and how specific responses are achieved downstream of Cdc42. Furthermore, some of the Cdc42 GEFs and one of the GAPs identified to date appear to partially overlap at the lateral junctions. An interesting possibility is that these junctional domains are heterogeneous and consist of a collection of co-existing discrete molecular platforms, including some containing active Cdc42 and others where it is inhibited. These domains might correlate with stages of junction maturation and thus different pools of junctional proteins, or might reflect that their dynamics is linked to endocytosis or membrane delivery. It is also possible that GEFs and GAPs might exchange within these discrete molecular platforms, thus dynamically regulating $\mathrm{Cdc} 42$. Super-resolution approaches and single-molecule tracking will help to test these hypotheses and elucidate how exactly Cdc42 activation and inactivation contribute to the morphogenesis and maintenance of epithelial structures. Furthermore, determining the stoichiometry of the canonical epithelial polarity complexes that lie downstream of $\mathrm{Cdc} 42$, and the biophysical properties of their constituent proteins, will be required to truly understand the mechanisms of epithelial polarity and morphogenesis.

\section{Acknowledgements}

The authors would like to thank Vania Braga, Nathan Goehring and Karl Matter for their input in preparing the manuscript.

\section{Competing interests}

The authors declare no competing or financial interests.

\section{Funding}

This work was funded by a Medical Research Council grant to F.P. (MC UU 12018/3 and MC UU 00012/3).

\section{Supplementary information}

Supplementary information available online at

http://jcs.biologists.org/lookup/doi/10.1242/jcs.217869.supplemental

\section{References}

Aceto, D., Beers, M. and Kemphues, K. J. (2006). Interaction of PAR-6 with CDC-42 is required for maintenance but not establishment of PAR asymmetry in C. elegans. Dev. Biol. 299, 386-397. doi:10.1016/j.ydbio.2006.08.002 
Adams, A. E., Johnson, D. I., Longnecker, R. M., Sloat, B. F. and Pringle, J. R. (1990). CDC42 and CDC43, two additional genes involved in budding and the establishment of cell polarity in the yeast Saccharomyces cerevisiae. J. Cell Biol. 111, 131-142. doi:10.1083/jcb.111.1.131

Ahmed, S. M. and Macara, I. G. (2017). The Par3 polarity protein is an exocys receptor essential for mammary cell survival. Nat. Commun. 8, 14867. doi:10. 1038/ncomms 14867

Anderson, D. C., Gill, J. S., Cinalli, R. M. and Nance, J. (2008). Polarization of the C. elegans embryo by RhoGAP-mediated exclusion of PAR- 6 from cell contacts. Science 320, 1771-1774. doi:10.1126/science.1156063

Apodaca, G., Gallo, L. I. and Bryant, D. M. (2012). Role of membrane traffic in the generation of epithelial cell asymmetry. Nat. Cell Biol. 14, 1235-1243. doi:10. 1038/ncb2635

Asano, A., Asano, K., Sasaki, H., Furuse, M. and Tsukita, S. (2003). Claudins in Caenorhabditis elegans: their distribution and barrier function in the epithelium. Curr. Biol. 13, 1042-1046. doi:10.1016/S0960-9822(03)00395-6

Aspenström, P., Lindberg, U. and Hall, A. (1996). Two GTPases, Cdc42 and Rac bind directly to a protein implicated in the immunodeficiency disorder WiskottAldrich syndrome. Curr. Biol. 6, 70-75. doi:10.1016/S0960-9822(02)00423-2

Beatty, A., Morton, D. G. and Kemphues, K. (2013). PAR-2, LGL-1 and the CDC42 GAP CHIN-1 act in distinct pathways to maintain polarity in the C. elegans embryo. Development 140, 2005-2014. doi:10.1242/dev.088310

Bendezú, F. O., Vincenzetti, V., Vavylonis, D., Wyss, R., Vogel, H. and Martin, S. G. (2015). Spontaneous Cdc42 polarization independent of GDI-mediated extraction and actin-based trafficking. PLoS Biol. 13, e1002097. doi:10.1371/ journal.pbio. 1002097

Benton, R. and St Johnston, D. (2003). Drosophila PAR-1 and 14-3-3 inhibit Bazooka/PAR-3 to establish complementary cortical domains in polarized cells. Cell 115, 691-704. doi:10.1016/S0092-8674(03)00938-3

Böhm, H., Brinkmann, V., Drab, M., Henske, A. and Kurzchalia, T. V. (1997) Mammalian homologues of C. elegans PAR-1 are asymmetrically localized in epithelial cells and may influence their polarity. Curr. Biol. 7, 603-606. doi:10. 1016/S0960-9822(06)00260-0

Bokoch, G. M. (2003). Biology of the p21-activated kinases. Annu. Rev. Biochem 72, 743-781. doi:10.1146/annurev.biochem.72.121801.161742

Bonello, T. T., Perez-Vale, K. Z., Sumigray, K. D. and Peifer, M. (2018). Rap1 acts via multiple mechanisms to position Canoe and adherens junctions and mediate apical-basal polarity establishment. Development 145, dev157941. doi:10.1242/ dev.157941

Bose, I., Irazoqui, J. E., Moskow, J. J., Bardes, E. S. G., Zyla, T. R. and Lew, D. J. (2001). Assembly of scaffold-mediated complexes containing Cdc42p, the exchange factor Cdc24p, and the effector Cla4p required for cell cycleregulated phosphorylation of Cdc24p. J. Biol. Chem. 276, 7176-7186. doi:10. 1074/jbc.M010546200

Braga, V. (2016). Spatial integration of E-cadherin adhesion, signalling and the epithelial cytoskeleton. Curr. Opin. Cell Biol. 42, 138-145. doi:10.1016/j.ceb.2016. 07.006

Bruurs, L. J., Zwakenberg, S., van der Net, M. C., Zwartkruis, F. J. and Bos, J. L. (2017). A two-tiered mechanism enables localized Cdc42 signaling during enterocyte polarization. Mol. Cell. Biol. 37, e00547-16. doi:10.1128/MCB.00547-16

Bryant, D. M., Datta, A., Rodriguez-Fraticelli, A. E., Peränen, J., MartínBelmonte, F. and Mostov, K. E. (2010). A molecular network for de novo generation of the apical surface and lumen. Nat. Cell Biol. 12, 1035-1045. doi:10. $1038 /$ ncb2106

Bulgakova, N. A. and Knust, E. (2009). The Crumbs complex: from epithelial-cell polarity to retinal degeneration. J. Cell Sci. 122, 2587-2596. doi:10.1242/jcs. 023648

Burbelo, P. D., Drechsel, D. and Hall, A. (1995). A conserved binding motif defines numerous candidate target proteins for both Cdc42 and Rac GTPases. J. Biol. Chem. 270, 29071-29074. doi:10.1074/jbc.270.49.29071

Chan, E. and Nance, J. (2013). Mechanisms of CDC-42 activation during contactinduced cell polarization. J. Cell Sci. 126, 1692-1702. doi:10.1242/jcs.124594

Cheeks, R. J., Canman, J. C., Gabriel, W. N., Meyer, N., Strome, S. and Goldstein, B. (2004). C. elegans PAR proteins function by mobilizing and stabilizing asymmetrically localized protein complexes. Curr. Biol. 14, 851-862. doi:10.1016/j.cub.2004.05.022

Chen, J., Sayadian, A.-C., Lowe, N., Lovegrove, H. E. and St Johnston, D. (2018). An alternative mode of epithelial polarity in the Drosophila midgut. PLoS Biol. 16, e3000041. doi:10.1371/journal.pbio.3000041

Coopman, P. and Djiane, A. (2016). Adherens junction and E-Cadherin complex regulation by epithelial polarity. Cell. Mol. Life Sci. 73, 3535-3553. doi:10.1007/ s00018-016-2260-8

Crawley, S. W., Mooseker, M. S. and Tyska, M. J. (2014). Shaping the intestinal brush border. J. Cell Biol. 207, 441-451. doi:10.1083/jcb.201407015

Dermietzel, R., Hwang, T. K. and Spray, D. S. (1990). The gap junction family: structure, function and chemistry. Anat. Embryol. 182, 517-528. doi:10.1007/ BF00186458

Diekmann, D., Brill, S., Garrett, M. D., Totty, N., Hsuan, J., Monfries, C., Hall, C., Lim, L. and Hall, A. (1991). Bcr encodes a GTPase-activating protein for p21rac. Nature 351, 400-402. doi:10.1038/351400a0
D'Souza, T., Indig, F. E. and Morin, P. J. (2007). Phosphorylation of claudin-4 by PKCepsilon regulates tight junction barrier function in ovarian cancer cells. Exp. Cell Res. 313, 3364-3375. doi:10.1016/j.yexcr.2007.06.026

Durgan, J., Kaji, N., Jin, D. and Hall, A. (2011). Par6B and atypical PKC regulate mitotic spindle orientation during epithelial morphogenesis. J. Biol. Chem. 286 , 12461-12474. doi:10.1074/jbc.M110.174235

Ebnet, K., Suzuki, A., Ohno, S. and Vestweber, D. (2004). Junctional adhesion molecules (JAMs): more molecules with dual functions? J. Cell Sci. 117, 19-29. doi:10.1242/jcs.00930

Elbediwy, A., Zhang, Y., Cobbaut, M., Riou, P., Tan, R. S., Roberts, S. K., Tynan, C., George, R., Kjaer, S., Martin-Fernandez, M. L. et al. (2019). The Rho family GEF FARP2 is activated by $\mathrm{aPKC}_{1}$ to control tight junction formation and polarity J. Cell Sci. 132, jcs223743. doi:10.1242/jcs.223743

Elbediwy, A., Zihni, C., Terry, S. J., Clark, P., Matter, K. and Balda, M. S. (2012) Epithelial junction formation requires confinement of Cdc42 activity by a novel SH3BP1 complex. J. Cell Biol. 198, 677-693. doi:10.1083/jcb.201202094

Erickson, J. W., Zhang, C.-J., Kahn, R. A., Evans, T. and Cerione, R. A. (1996) Mammalian Cdc42 is a brefeldin A-sensitive component of the Golgi apparatus. J. Biol. Chem. 271, 26850-26854. doi:10.1074/jbc.271.43.26850

Etienne-Manneville, S. (2004). Cdc42 - the centre of polarity. J. Cell Sci. 117 1291-1300. doi:10.1242/jcs.01115

Evangelista, M., Blundell, K., Longtine, M. S., Chow, C. J., Adames, N., Pringle, J. R., Peter, M. and Boone, C. (1997). Bni1p, a yeast formin linking cdc42p and the actin cytoskeleton during polarized morphogenesis. Science 276, 118-122. doi:10.1126/science.276.5309.118

Evangelista, M., Pruyne, D., Amberg, D. C., Boone, C. and Bretscher, A. (2002) Formins direct Arp2/3-independent actin filament assembly to polarize cell growth in yeast. Nat. Cell Biol. 4, 260-269. doi:10.1038/ncb718

Fukuhara, A., Shimizu, K., Kawakatsu, T., Fukuhara, T. and Takai, Y. (2003) Involvement of nectin-activated $\mathrm{Cdc} 42$ small $\mathrm{G}$ protein in organization of adherens and tight junctions in Madin-Darby canine kidney cells. J. Biol. Chem. 278 51885-51893. doi:10.1074/jbc.M308015200

Gao, L. and Macara, I. G. (2004). Isoforms of the polarity protein par6 have distinct functions. J. Biol. Chem. 279, 41557-41562. doi:10.1074/jbc.M403723200

Garrard, S. M., Capaldo, C. T., Gao, L., Rosen, M. K., Macara, I. G. and Tomchick, D. R. (2003). Structure of Cdc42 in a complex with the GTPasebinding domain of the cell polarity protein, Par6. EMBO J. 22, 1125-1133. doi:10. 1093/emboj/cdg110

Garrod, D. and Chidgey, M. (2008). Desmosome structure, composition and function. Biochim. Biophys. Acta 1778, 572-587. doi:10.1016/j.bbamem.2007.07. 014

Gauthier, N. C., Monzo, P., Gonzalez, T., Doye, A., Oldani, A., Gounon, P., Ricci, V., Cormont, M. and Boquet, P. (2007). Early endosomes associated with dynamic $\mathrm{F}$-actin structures are required for late trafficking of $\mathrm{H}$. pylori VacA toxin. J Cell Biol 177, 343-354. doi:10.1083/jcb.200609061

Georgiou, M., Marinari, E., Burden, J. and Baum, B. (2008). Cdc42, Par6, and aPKC regulate Arp2/3-mediated endocytosis to control local adherens junction stability. Curr. Biol. 18, 1631-1638. doi:10.1016/j.cub.2008.09.029

Goehring, N. W. and Grill, S. W. (2013). Cell polarity: mechanochemical patterning Trends Cell Biol. 23, 72-80. doi:10.1016/j.tcb.2012.10.009

Goehring, N. W., Trong, P. K., Bois, J. S., Chowdhury, D., Nicola, E. M., Hyman, A. A. and Grill, S. W. (2011). Polarization of PAR proteins by advective triggering of a pattern-forming system. Science 334, 1137-1141. doi:10.1126/science. 1208619

Goryachev, A. B. and Pokhilko, A. V. (2008). Dynamics of Cdc42 network embodies a Turing-type mechanism of yeast cell polarity. FEBS Lett. $\mathbf{5 8 2}$ 1437-1443. doi:10.1016/j.febslet.2008.03.029

Gotta, M., Abraham, M. C. and Ahringer, J. (2001). CDC-42 controls early cell polarity and spindle orientation in C. elegans. Curr. Biol. 11, 482-488. doi:10.1016/ S0960-9822(01)00142-7

Griffith, L. G. and Swartz, M. A. (2006). Capturing complex 3D tissue physiology in vitro. Nat. Rev. Mol. Cell Biol. 7, 211-224. doi:10.1038/nrm1858

Gumbiner, B. and Simons, K. (1986). A functional assay for proteins involved in establishing an epithelial occluding barrier: identification of a uvomorulin-like polypeptide. J. Cell Biol. 102, 457-468. doi:10.1083/jcb.102.2.457

Hall, A. (2012). Rho family GTPases. Biochem. Soc. Trans. 40, 1378-1382. doi:10. 1042/BST20120103

Harrell, J. R. and Goldstein, B. (2011). Internalization of multiple cells during C. elegans gastrulation depends on common cytoskeletal mechanisms but different cell polarity and cell fate regulators. Dev. Biol. 350, 1-12. doi:10.1016/j. ydbio.2010.09.012

Harris, K. P. and Tepass, U. (2008). Cdc42 and Par proteins stabilize dynamic adherens junctions in the Drosophila neuroectoderm through regulation of apical endocytosis. J. Cell Biol. 183, 1129-1143. doi:10.1083/jcb.200807020

Harris, K. P. and Tepass, U. (2010a). Cdc42 and vesicle trafficking in polarized cells. Traffic 11, 1272-1279. doi:10.1111/j.1600-0854.2010.01102.x

Harris, T. J. C. and Tepass, U. (2010b). Adherens junctions: from molecules to morphogenesis. Nat. Rev. Mol. Cell Biol. 11, 502-514. doi:10.1038/nrm2927 
Hart, M. J., Eva, A., Evans, T., Aaronson, S. A. and Cerione, R. A. (1991) Catalysis of guanine nucleotide exchange on the $\mathrm{CDC} 42 \mathrm{Hs}$ protein by the $\mathrm{dbl}$ oncogene product. Nature 354, 311-314. doi:10.1038/354311a0

Hayase, J., Kamakura, S., Iwakiri, Y., Yamaguchi, Y., Izaki, T., Ito, T. and Sumimoto, H. (2013). The WD40 protein Morg1 facilitates Par6-aPKC binding to Crb3 for apical identity in epithelial cells. J. Cell Biol. 200, 635-650. doi:10.1083/ jcb.201208150

Hirose, T., Izumi, Y., Nagashima, Y., Tamai-Nagai, Y., Kurihara, H., Sakai, T. Suzuki, Y., Yamanaka, T., Suzuki, A., Mizuno, K. et al. (2002). Involvement of ASIP/PAR-3 in the promotion of epithelial tight junction formation. J. Cell Sci. 115, 2485-2495.

Hoffman, G. R., Nassar, N. and Cerione, R. A. (2000). Structure of the Rho family GTP-binding protein Cdc42 in complex with the multifunctional regulator RhoGDI. Cell 100, 345-356. doi:10.1016/S0092-8674(00)80670-4

Hogan, C., Serpente, N., Cogram, P., Hosking, C. R., Bialucha, C. U., Feller S. M., Braga, V. M. M., Birchmeier, W. and Fujita, Y. (2004). Rap1 regulates the formation of E-cadherin-based cell-cell contacts. Mol. Cell. Biol. 24, 6690-6700. doi:10.1128/MCB.24.15.6690-6700.2004

Hurd, T. W., Gao, L., Roh, M. H., Macara, I. G. and Margolis, B. (2003). Direct interaction of two polarity complexes implicated in epithelial tight junction assembly. Nat. Cell Biol. 5, 137-142. doi:10.1038/ncb923

Hurov, J. B., Watkins, J. L. and Piwnica-Worms, H. (2004). Atypical PKC phosphorylates PAR-1 kinases to regulate localization and activity. Curr. Biol. 14 736-741. doi:10.1016/j.cub.2004.04.007

Hutterer, A., Betschinger, J., Petronczki, M. and Knoblich, J. A. (2004) Sequential roles of Cdc42, Par-6, aPKC, and Lgl in the establishment of epithelial polarity during Drosophila embryogenesis. Dev. Cell 6, 845-854. doi:10.1016/j. devcel.2004.05.003

Iden, S., Misselwitz, S., Peddibhotla, S. S. D., Tuncay, H., Rehder, D., Gerke, V., Robenek, H., Suzuki, A. and Ebnet, K. (2012). aPKC phosphorylates JAM-A a Ser285 to promote cell contact maturation and tight junction formation. J. Cell Biol. 196, 623-639. doi:10.1083/jcb.201104143

Ishiuchi, T. and Takeichi, M. (2011). Willin and Par3 cooperatively regulate epithelial apical constriction through aPKC-mediated ROCK phosphorylation. Nat. Cell Biol. 13, 860-866. doi:10.1038/ncb2274

Jaffe, A. B., Kaji, N., Durgan, J. and Hall, A. (2008). Cdc42 controls spindle orientation to position the apical surface during epithelial morphogenesis. J. Cell Biol. 183, 625-633. doi:10.1083/jcb.200807121

Jain, S., Suzuki, T., Seth, A., Samak, G. and Rao, R. (2011). Protein kinase Czeta phosphorylates occludin and promotes assembly of epithelial tight junctions. Biochem. J. 437, 289-299. doi:10.1042/BJ20110587

Jewett, C. E. and Prekeris, R. (2018). Insane in the apical membrane: trafficking events mediating apicobasal epithelial polarity during tube morphogenesis. Traffic 19, 666-678. doi:10.1111/tra.12579

Jin, D., Durgan, J. and Hall, A. (2015). Functional cross-talk between Cdc42 and two downstream targets, Par6B and PAK4. Biochem. J. 467, 293-302. doi:10. 1042/BJ20141352

Joberty, G., Petersen, C., Gao, L. and Macara, I. G. (2000). The cell-polarity protein Par6 links Par3 and atypical protein kinase C to Cdc42. Nat. Cell Biol. 2 531-539. doi:10.1038/35019573

Johnson, D. I. and Pringle, J. R. (1990). Molecular characterization of CDC42, a Saccharomyces cerevisiae gene involved in the development of cell polarity. J. Cell Biol. 111, 143-152. doi:10.1083/jcb.111.1.143

Kay, A. J. and Hunter, C. P. (2001). CDC-42 regulates PAR protein localization and function to control cellular and embryonic polarity in C. elegans. Curr. Biol. 11, 474-481. doi:10.1016/S0960-9822(01)00141-5

Kemphues, K. J., Priess, J. R., Morton, D. G. and Cheng, N. S. (1988). Identification of genes required for cytoplasmic localization in early $\mathrm{C}$. elegans embryos. Cell 52, 311-320. doi:10.1016/S0092-8674(88)80024-2

Kempkens, O., Medina, E., Fernandez-Ballester, G., Ozuyaman, S., Le Bivic, A. Serrano, L. and Knust, E. (2006). Computer modelling in combination with in vitro studies reveals similar binding affinities of Drosophila Crumbs for the PDZ domains of Stardust and DmPar-6. Eur. J. Cell Biol. 85, 753-767. doi:10.1016/j. ejcb.2006.03.003

Klinkert, K., Rocancourt, M., Houdusse, A. and Echard, A. (2016). Rab35 GTPase couples cell division with initiation of epithelial apico-basal polarity and lumen opening. Nat. Commun. 7, 11166. doi:10.1038/ncomms11166

Klompstra, D., Anderson, D. C., Yeh, J. Y., Zilberman, Y. and Nance, J. (2015) An instructive role for $\mathrm{C}$. elegans $\mathrm{E}$-cadherin in translating cell contact cues into cortical polarity. Nat. Cell Biol. 17, 726-735. doi:10.1038/ncb3168

Klünder, B., Freisinger, T., Wedlich-Söldner, R. and Frey, E. (2013). GDImediated cell polarization in yeast provides precise spatial and temporal control of Cdc42 signaling. PLoS Comput. Biol. 9, e1003396. doi:10.1371/journal.pcbi. 1003396

Knust, E. and Bossinger, O. (2002). Composition and formation of intercellular junctions in epithelial cells. Science 298, 1955-1959. doi:10.1126/science. 1072161

Kolluri, R., Tolias, K. F., Carpenter, C. L., Rosen, F. S. and Kirchhausen, T. (1996). Direct interaction of the Wiskott-Aldrich syndrome protein with the
GTPase Cdc42. Proc. Natl. Acad. Sci. USA 93, 5615-5618. doi:10.1073/pnas 93.11.5615

Krahn, M. P., Bückers, J., Kastrup, L. and Wodarz, A. (2010). Formation of a Bazooka-Stardust complex is essential for plasma membrane polarity in epithelia. J. Cell Biol. 190, 751-760. doi:10.1083/jcb.201006029

Kumfer, K. T., Cook, S. J., Squirrell, J. M., Eliceiri, K. W., Peel, N., O'Connell, K. F. and White, J. G. (2010). CGEF-1 and CHIN-1 regulate CDC-42 activity during asymmetric division in the Caenorhabditis elegans embryo. Mol. Biol. Cell 21, 266-277. doi:10.1091/mbc.e09-01-0060

Labouesse, M. (2006). Epithelial junctions and attachments. WormBook, 1-21. 10. 1895/wormbook.1.56.1

Lecuit, T. and Yap, A. S. (2015). E-cadherin junctions as active mechanica integrators in tissue dynamics. Nat. Cell Biol. 17, 533-539. doi:10.1038/ncb3136 Leibfried, A., Fricke, R., Morgan, M. J., Bogdan, S. and Bellaiche, Y. (2008) Drosophila Cip4 and WASp define a branch of the Cdc42-Par6-aPKC pathway regulating E-cadherin endocytosis. Curr. Biol. 18, 1639-1648. doi:10.1016/j.cub. 2008.09.063

Lemmers, C., Michel, D., Lane-Guermonprez, L., Delgrossi, M.-H., Médina, E. Arsanto, J.-P. and Le Bivic, A. (2004). CRB3 binds directly to Par6 and regulates the morphogenesis of the tight junctions in mammalian epithelial cells. Mol. Biol. Cell 15, 1324-1333. doi:10.1091/mbc.e03-04-0235

Li, D., Mangan, A., Cicchini, L., Margolis, B. and Prekeris, R. (2014). FIP5 phosphorylation during mitosis regulates apical trafficking and lumenogenesis EMBO Rep. 15, 428-437. doi:10.1002/embr.201338128

Lin, D., Edwards, A. S., Fawcett, J. P., Mbamalu, G., Scott, J. D. and Pawson, T (2000). A mammalian PAR-3-PAR-6 complex implicated in Cdc42/Rac1 and aPKC signalling and cell polarity. Nat. Cell Biol. 2, 540-547. doi:10.1038/ 35019582

Lin, Q., Fuji, R. N., Yang, W. and Cerione, R. A. (2003). RhoGDI is required fo Cdc42-mediated cellular transformation. Curr. Biol. 13, 1469-1479. doi:10.1016/ S0960-9822(03)00613-4

Machesky, L. M. and Insall, R. H. (1998). Scar1 and the related Wiskott-Aldrich syndrome protein, WASP, regulate the actin cytoskeleton through the Arp2/3 complex. Curr. Biol. 8, 1347-1356. doi:10.1016/S0960-9822(98)00015-3

Malicki, J. J. and Johnson, C. A. (2017). The cilium: cellular antenna and central processing unit. Trends Cell Biol. 27, 126-140. doi:10.1016/j.tcb.2016.08.002

Mangan, A. J., Sietsema, D. V., Li, D., Moore, J. K., Citi, S. and Prekeris, R. (2016). Cingulin and actin mediate midbody-dependent apical lumen formation during polarization of epithelial cells. Nat. Commun. 7, 12426. doi:10.1038/ ncomms12426

Manser, E., Leung, T., Salihuddin, H., Zhao, Z.-S. and Lim, L. (1994). A brain serine/threonine protein kinase activated by Cdc42 and Rac1. Nature 367, 40-46. doi:10.1038/367040a0

Marston, D. J., Higgins, C. D., Peters, K. A., Cupp, T. D., Dickinson, D. J., Pani, A. M., Moore, R. P., Cox, A. H., Kiehart, D. P. and Goldstein, B. (2016). MRCK-1 Drives Apical Constriction in C. elegans by Linking Developmental Patterning to Force Generation. Curr. Biol. 26, 2079-2089. doi:10.1016/j.cub.2016.06.010

Martin-Belmonte, F., Gassama, A., Datta, A., Yu, W., Rescher, U., Gerke, V. and Mostov, K. (2007). PTEN-mediated apical segregation of phosphoinositides controls epithelial morphogenesis through Cdc42. Cell 128, 383-397. doi:10. 1016/j.cell.2006.11.051

Matter, K. and Balda, M. S. (2003). Signalling to and from tight junctions. Nat. Rev Mol. Cell Biol. 4, 225-236. doi:10.1038/nrm1055

Menzel, N., Melzer, J., Waschke, J., Lenz, C., Wecklein, H., Lochnit, G., Drenckhahn, D. and Raabe, T. (2008). The Drosophila p21-activated kinase Mb modulates DE-cadherin-mediated cell adhesion by phosphorylation of Armadillo. Biochem. J. 416, 231-241. doi:10.1042/BJ20080465

Mitchison, H. M. and Valente, E. M. (2017). Motile and non-motile cilia in human pathology: from function to phenotypes. J. Pathol. 241, 294-309. doi:10.1002/ path.4843

Mitsushima, M., Toyoshima, F. and Nishida, E. (2009). Dual role of Cdc42 in spindle orientation control of adherent cells. Mol. Cell. Biol. 29, 2816-2827. doi:10. 1128/MCB.01713-08

Morais-de-Sá, E., Mirouse, V. and St Johnston, D. (2010). aPKC phosphorylation of Bazooka defines the apical/lateral border in Drosophila epithelial cells. Cell. 141, 509-523. doi:10.1016/j.cell.2010.02.040

Motegi, F. and Seydoux, G. (2013). The PAR network: redundancy and robustness in a symmetry-breaking system. Philos. Trans. R. Soc. Lond. B Biol. Sci. 368 , 20130010. doi:10.1098/rstb.2013.0010

Mrozowska, P. S. and Fukuda, M. (2016). Regulation of podocalyxin trafficking by Rab small GTPases in 2D and 3D epithelial cell cultures. J. Cell Biol. 213, 355-369. doi:10.1083/jcb.201512024

Munro, E., Nance, J. and Priess, J. R. (2004). Cortical flows powered by asymmetrical contraction transport PAR proteins to establish and maintain anterior-posterior polarity in the early C. elegans embryo. Dev. Cell 7, 413-424 doi:10.1016/j.devcel.2004.08.001

Musch, A., Cohen, D., Kreitzer, G. and Rodriguez-Boulan, E. (2001). cdc42 regulates the exit of apical and basolateral proteins from the trans-Golgi network EMBO J. 20, 2171-2179. doi:10.1093/emboj/20.9.2171 
Nobes, C. D. and Hall, A. (1995). Rho, rac, and cdc42 GTPases regulate the assembly of multimolecular focal complexes associated with actin stress fibers lamellipodia, and filopodia. Cell 81, 53-62. doi:10.1016/0092-8674(95)90370-4

Noda, Y., Takeya, R., Ohno, S., Naito, S., Ito, T. and Sumimoto, H. (2001). Human homologues of the Caenorhabditis elegans cell polarity protein PAR6 as an adaptor that links the small GTPases Rac and Cdc42 to atypical protein kinase C. Genes Cells 6, 107-119. doi:10.1046/j.1365-2443.2001.00404.x

Nunes de Almeida, F., Walther, R. F., Presse, M., Vlassaks, E. and Pichaud, F. (2019). Cdc42 promotes epithelial morphogenesis by coupling Par-complex and Crumbs recruitment via Par6-aPKC. bioRxiv, 513028. doi:10.1101/513028

Otani, T., Ichii, T., Aono, S. and Takeichi, M. (2006). Cdc42 GEF Tuba regulates the junctional configuration of simple epithelial cells. J. Cell Biol. 175, 135-146. doi:10.1083/jcb.200605012

Peng, J., Wallar, B. J., Flanders, A., Swiatek, P. J. and Alberts, A. S. (2003) Disruption of the Diaphanous-related formin Drf1 gene encoding mDia1 reveals a role for Drf3 as an effector for Cdc42. Curr. Biol. 13, 534-545. doi:10.1016/S0960 9822(03)00170-2

Peterson, J., Zheng, Y., Bender, L., Myers, A., Cerione, R. and Bender, A. (1994) Interactions between the bud emergence proteins Bem1p and Bem2p and Rhotype GTPases in yeast. J. Cell Biol. 127, 1395-1406. doi:10.1083/jcb.127.5.1395

Peterson, F. C., Penkert, R. R., Volkman, B. F. and Prehoda, K. E. (2004). Cdc42 regulates the Par-6 PDZ domain through an allosteric CRIB-PDZ transition. Mol. Cell 13, 665-676. doi:10.1016/S1097-2765(04)00086-3

Petronczki, M. and Knoblich, J. A. (2001). DmPAR-6 directs epithelial polarity and asymmetric cell division of neuroblasts in Drosophila. Nat. Cell Biol. 3, 43-49. doi:10.1038/35050550

Pinal, N., Goberdhan, D. C., Collinson, L., Fujita, Y., Cox, I. M., Wilson, C. and Pichaud, F. (2006). Regulated and polarized Ptdlns(3,4,5)P3 accumulation is essential for apical membrane morphogenesis in photoreceptor epithelial cells. Curr. Biol. 16, 140-149. doi:10.1016/j.cub.2005.11.068

Pirraglia, C., Walters, J. and Myat, M. M. (2010). Pak1 control of E-cadherin endocytosis regulates salivary gland lumen size and shape. Development 137 4177-4189. doi:10.1242/dev.048827

Plant, P. J., Fawcett, J. P., Lin, D. C. C., Holdorf, A. D., Binns, K., Kulkarni, S. and Pawson, T. (2003). A polarity complex of mPar-6 and atypical PKC binds phosphorylates and regulates mammalian Lgl. Nat. Cell Biol. 5, 301-308. doi:10. 1038/ncb948

Pruyne, D., Evangelista, M., Yang, C., Bi, E., Zigmond, S., Bretscher, A. and Boone, C. (2002). Role of formins in actin assembly: nucleation and barbed-end association. Science 297, 612-615. doi:10.1126/science.1072309

Pruyne, D., Legesse-Miller, A., Gao, L., Dong, Y. and Bretscher, A. (2004) Mechanisms of polarized growth and organelle segregation in yeast. Annu. Rev. Cell Dev. Biol. 20, 559-591. doi:10.1146/annurev.cellbio.20.010403.103108

Qin, Y., Meisen, W. H., Hao, Y. and Macara, I. G. (2010). Tuba, a Cdc42 GEF, is required for polarized spindle orientation during epithelial cyst formation. J. Cell Biol. 189, 661-669. doi:10.1083/jcb.201002097

Rane, C. K. and Minden, A. (2014). P21 activated kinases: structure, regulation, and functions. Small GTPases 5, e28003. doi:10.4161/sgtp.28003

Ranganathan, R. and Ross, E. M. (1997). PDZ domain proteins: scaffolds for signaling complexes. Curr. Biol. 7, R770-R773. doi:10.1016/S09609822(06)00401-5

Ridley, A. J. (2015). Rho GTPase signalling in cell migration. Curr. Opin. Cell Biol. 36, 103-112. doi:10.1016/j.ceb.2015.08.005

Ridley, A. J. and Hall, A. (1992). The small GTP-binding protein rho regulates the assembly of focal adhesions and actin stress fibers in response to growth factors. Cell 70, 389-399. doi:10.1016/0092-8674(92)90163-7

Ridley, A. J., Paterson, H. F., Johnston, C. L., Diekmann, D. and Hall, A. (1992) The small GTP-binding protein rac regulates growth factor-induced membrane ruffling. Cell 70, 401-410. doi:10.1016/0092-8674(92)90164-8

Roberts, P. J., Mitin, N., Keller, P. J., Chenette, E. J., Madigan, J. P., Currin R. O., Cox, A. D., Wilson, O., Kirschmeier, P. and Der, C. J. (2008). Rho Family GTPase modification and dependence on CAAX motif-signaled posttranslational modification. J. Biol. Chem. 283, 25150-25163. doi:10.1074/jbc.M800882200

Rodriguez, J., Peglion, F., Martin, J., Hubatsch, L., Reich, J., Hirani, N., Gubieda, A. G., Roffey, J., Fernandes, A. R., St Johnston, D. et al. (2017) aPKC cycles between functionally distinct PAR protein assemblies to drive cell polarity. Dev. Cell 42, 400-415.e9. doi:10.1016/j.devcel.2017.07.007

Rodriguez-Boulan, E. and Macara, I. G. (2014). Organization and execution of the epithelial polarity programme. Nat. Rev. Mol. Cell Biol. 15, 225-242. doi:10.1038/ nrm3775

Rodriguez-Fraticelli, A. E., Vergarajauregui, S., Eastburn, D. J., Datta, A., Alonso, M. A., Mostov, K. and Martín-Belmonte, F. (2010). The Cdc42 GEF Intersectin 2 controls mitotic spindle orientation to form the lumen during epithelia morphogenesis. J. Cell Biol. 189, 725-738. doi:10.1083/jcb.201002047

Rohrschneider, M. R. and Nance, J. (2009). Polarity and cell fate specification in the control of Caenorhabditis elegans gastrulation. Dev. Dyn. 238, 789-796. doi:10.1002/dvdy.21893

Röper, K. (2012). Anisotropy of Crumbs and aPKC drives myosin cable assembly during tube formation. Dev. Cell 23, 939-953. doi:10.1016/j.devcel.2012.09.013
Sagot, I., Klee, S. K. and Pellman, D. (2002a). Yeast formins regulate cell polarity by controlling the assembly of actin cables. Nat. Cell Biol. 4, 42-50. doi:10.1038/ ncb719

Sagot, I., Rodal, A. A., Moseley, J., Goode, B. L. and Pellman, D. (2002b). An actin nucleation mechanism mediated by Bni1 and profilin. Nat. Cell Biol. 4 626-631. doi:10.1038/ncb834

Schneeberger, D. and Raabe, T. (2003). Mbt, a Drosophila PAK protein, combines with $\mathrm{Cdc} 42$ to regulate photoreceptor cell morphogenesis. Development 130 , 427-437. doi:10.1242/dev.00248

Selamat, W., Tay, P.-L. F., Baskaran, Y. and Manser, E. (2015). The Cdc42 effector kinase PAK4 localizes to cell-cell junctions and contributes to establishing cell polarity. PLOS ONE 10, e0129634. doi:10.1371/journal.pone.0129634

Shitara, A., Malec, L., Ebrahim, S., Chen, D., Bleck, C., Hoffman, M. P. and Weigert, R. (2019). Cdc42 negatively regulates endocytosis during apical membrane maintenance in live animals. Mol. Biol. Cell 30, 324-332. doi:10. 1091/mbc.E18-10-0615

Slaughter, B. D., Das, A., Schwartz, J. W., Rubinstein, B. and Li, R. (2009). Dual modes of cdc42 recycling fine-tune polarized morphogenesis. Dev. Cell 17 823-835. doi:10.1016/j.devcel.2009.10.022

St Johnston, D. and Ahringer, J. (2010). Cell polarity in eggs and epithelia: parallels and diversity. Cell 141, 757-774. doi:10.1016/j.cell.2010.05.011

Steinbacher, T. and Ebnet, K. (2018). The regulation of junctional actin dynamics by cell adhesion receptors. Histochem. Cell Biol. 150, 341-350. doi:10.1007/ s00418-018-1691-8

Suzuki, A., Yamanaka, T., Hirose, T., Manabe, N., Mizuno, K., Shimizu, M. Akimoto, K., Izumi, Y., Ohnishi, T. and Ohno, S. (2001). Atypical protein kinase $\mathrm{C}$ is involved in the evolutionarily conserved par protein complex and plays a critical role in establishing epithelia-specific junctional structures. J. Cell Biol. 152 1183-1196. doi:10.1083/jcb.152.6.1183

Suzuki, A., Hirata, M., Kamimura, K., Maniwa, R., Yamanaka, T., Mizuno, K. Kishikawa, M., Hirose, H., Amano, Y., Izumi, N. et al. (2004). aPKC acts upstream of PAR-1b in both the establishment and maintenance of mammalian epithelial polarity. Curr. Biol. 14, 1425-1435. doi:10.1016/j.cub.2004.08.021

Symons, M., Derry, J. M. J., Karlak, B., Jiang, S., Lemahieu, V., McCormick, F., Francke, U. and Abo, A. (1996). Wiskott-Aldrich syndrome protein, a nove effector for the GTPase CDC42Hs, is implicated in actin polymerization. Cell 84 723-734. doi:10.1016/S0092-8674(00)81050-8

Tabuse, Y., Izumi, Y., Piano, F., Kemphues, K. J., Miwa, J. and Ohno, S. (1998) Atypical protein kinase $\mathrm{C}$ cooperates with $\mathrm{PAR}-3$ to establish embryonic polarity in Caenorhabditis elegans. Development 125, 3607-3614

Tang, V. W. and Brieher, W. M. (2013). FSGS3/CD2AP is a barbed-end capping protein that stabilizes actin and strengthens adherens junctions. J. Cell Biol. 203, 815-833. doi:10.1083/jcb.201304143

Tay, H. G., Ng, Y. W. and Manser, E. (2010). A vertebrate-specific Chp-PAK-PIX pathway maintains E-cadherin at adherens junctions during zebrafish epiboly. PLoS ONE 5, e10125. doi:10.1371/journal.pone.0010125

Tepass, U. (2012). The apical polarity protein network in Drosophila epithelial cells: regulation of polarity, junctions, morphogenesis, cell growth, and survival. Annu. Rev. Cell Dev. Biol. 28, 655-685. doi:10.1146/annurev-cellbio-092910-154033

Tepass, U., Tanentzapf, G., Ward, R. and Fehon, R. (2001). Epithelial cell polarity and cell junctions in Drosophila. Annu. Rev. Genet. 35, 747-784. doi:10.1146/ annurev.genet.35.102401.091415

Todaro, G. J., Lazar, G. K. and Green, H. (1965). The initiation of cell division in a contact-inhibited mammalian cell line. J. Cell. Physiol. 66, 325-333. doi:10.1002 jcp.1030660310

Tsukita, S., Furuse, M. and Itoh, M. (2001). Multifunctional strands in tight junctions. Nat. Rev. Mol. Cell Biol. 2, 285-293. doi:10.1038/35067088

Tyler, S. (2003). Epithelium-the primary building block for metazoan complexity. Integr. Comp. Biol. 43, 55-63. doi:10.1093/icb/43.1.55

Wallace, S. W., Durgan, J., Jin, D. and Hall, A. (2010). Cdc42 regulates apical junction formation in human bronchial epithelial cells through PAK4 and Par6B. Mol. Biol. Cell 21, 2996-3006. doi:10.1091/mbc.e10-05-0429

Walther, R. F. and Pichaud, F. (2010). Crumbs/DaPKC-dependent apical exclusion of Bazooka promotes photoreceptor polarity remodeling. Curr. Biol. 20 1065-1074. doi:10.1016/j.cub.2010.04.049

Walther, R. F., Burki, M., Pinal, N., Rogerson, C. and Pichaud, F. (2018). Rap1, Canoe and Mbt cooperate with Bazooka to promote zonula adherens assembly in the fly photoreceptor. J. Cell Sci. 131, jcs207779. doi:10.1242/jcs.207779

Walther, R. F., Nunes de Almeida, F., Vlassaks, E., Burden, J. J. and Pichaud, F. (2016). Pak4 Is required during epithelial polarity remodeling through regulating AJ stability and Bazooka retention at the ZA. Cell Rep 15, 45-53. doi:10.1016/j. celrep.2016.03.014

Wang, Q., Hurd, T. W. and Margolis, B. (2004). Tight junction protein Par6 interacts with an evolutionarily conserved region in the amino terminus of PALS1/stardust J. Biol. Chem. 279, 30715-30721. doi:10.1074/jbc.M401930200

Wang, S. C., Low, T. Y. F., Nishimura, Y., Gole, L., Yu, W. and Motegi, F. (2017) Cortical forces and CDC-42 control clustering of PAR proteins for Caenorhabditis elegans embryonic polarization. Nat. Cell Biol. 19, 988-995. doi:10.1038/ncb3577 Watts, J. L., Etemad-Moghadam, B., Guo, S., Boyd, L., Draper, B. W., Mello, C. C., Priess, J. R. and Kemphues, K. J. (1996). par-6, a gene involved in the 
establishment of asymmetry in early C. elegans embryos, mediates the asymmetric localization of PAR-3. Development 122, 3133-3140.

Wedlich-Soldner, R., Altschuler, S., Wu, L. and Li, R. (2003). Spontaneous cell polarization through actomyosin-based delivery of the Cdc42 GTPase. Science 299, 1231-1235. doi:10.1126/science.1080944

Wedlich-Soldner, R., Wai, S. C., Schmidt, T. and Li, R. (2004). Robust cell polarity is a dynamic state established by coupling transport and GTPase signaling. J. Cell Biol. 166, 889-900. doi:10.1083/jcb.200405061

Wells, C. D., Fawcett, J. P., Traweger, A., Yamanaka, Y., Goudreault, M., Elder, K., Kulkarni, S., Gish, G., Virag, C., Lim, C. et al. (2006). A Rich1/Amot complex regulates the Cdc42 GTPase and apical-polarity proteins in epithelial cells. Cell 125, 535-548. doi:10.1016/j.cell.2006.02.045

Whitney, D. S., Peterson, F. C. and Volkman, B. F. (2011). A conformational switch in the CRIB-PDZ module of Par-6. Structure 19, 1711-1722. doi:10.1016/j.str. 2011.07.018

Willenborg, C., Jing, J., Wu, C., Matern, H., Schaack, J., Burden, J. and Prekeris, R. (2011). Interaction between FIP5 and SNX18 regulates epithelial lumen formation. J. Cell Biol. 195, 71-86. doi:10.1083/jcb.201011112

Witte, K., Strickland, D. and Glotzer, M. (2017). Cell cycle entry triggers a switch between two modes of $\mathrm{Cdc} 42$ activation during yeast polarization. eLife $\mathbf{6}$, e26722. doi:10.7554/eLife.26722
Woods, B. and Lew, D. J. (2019). Polarity establishment by Cdc42: key roles for positive feedback and differential mobility. Small GTPases 10, 130-137. doi:10. 1080/21541248.2016.1275370

Yamada, K. M. and Cukierman, E. (2007). Modeling tissue morphogenesis and cancer in 3D. Cell 130, 601-610. doi:10.1016/j.cell.2007.08.006

Yasuda, S., Oceguera-Yanez, F., Kato, T., Okamoto, M., Yonemura, S., Terada, Y., Ishizaki, T. and Narumiya, S. (2004). Cdc42 and mDia3 regulate microtubule attachment to kinetochores. Nature 428, 767-771. doi:10.1038/nature02452

Zhang, X., Bi, E., Novick, P., Du, L., Kozminski, K. G., Lipschutz, J. H. and Guo, W. (2001). Cdc42 interacts with the exocyst and regulates polarized secretion. J. Biol. Chem. 276, 46745-46750. doi:10.1074/jbc.M107464200

Zhang, X., Orlando, K., He, B., Xi, F., Zhang, J., Zajac, A. and Guo, W. (2008). Membrane association and functional regulation of Sec3 by phospholipids and Cdc42. J. Cell Biol. 180, 145-158. doi:10.1083/jcb.200704128

Zihni, C., Munro, P. M. G., Elbediwy, A., Keep, N. H., Terry, S. J., Harris, J., Balda, M. S. and Matter, K. (2014). Dbl3 drives Cdc42 signaling at the apical margin to regulate junction position and apical differentiation. J. Cell Biol. 204, 111-127. doi:10.1083/jcb.201304064

Zihni, C., Vlassaks, E., Terry, S., Carlton, J., Leung, T. K. C., Olson, M., Pichaud, F., Balda, M. S. and Matter, K. (2017). An apical MRCK-driven morphogenetic pathway controls epithelial polarity. Nat. Cell Biol. 19, 1049-1060. doi:10.1038/ncb3592 
Table S1. Mammalian effectors of Cdc42

\begin{tabular}{|c|c|c|}
\hline Gene name & Function & References \\
\hline ACK/TNK2 & Actin organization & Manser et al., 1993 \\
\hline Borg1/CDC42EP2 & Actin organization, cell shape & $\begin{array}{l}\text { Hirsch et al., 2001; Joberty et } \\
\text { al., 1999; Joberty et al., } 2001\end{array}$ \\
\hline Borg2/CDC42EP3 & Actin organization, cell shape & $\begin{array}{l}\text { Hirsch et al., 2001; Joberty et } \\
\text { al., 1999; Joberty et al., } 2001\end{array}$ \\
\hline Borg3/CDC42EP5 & Actin organization, cell shape & $\begin{array}{l}\text { Hirsch et al., 2001; Joberty et } \\
\text { al., 1999; Joberty et al., } 2001\end{array}$ \\
\hline Borg4/CDC42EP4 & Actin organization & $\begin{array}{l}\text { Hirsch et al., 2001; Joberty et } \\
\text { al., } 1999\end{array}$ \\
\hline Borg5/CDC42EP1 & Actin organization & $\begin{array}{l}\text { Hirsch et al., 2001; Joberty et } \\
\text { al., } 1999\end{array}$ \\
\hline CEP2 & Pseudopodia formation & Hirsch et al., 2001 \\
\hline CEP5 & Pseudopodia formation & Hirsch et al., 2001 \\
\hline CIP4/TRIP10 & Actin organization & Aspenstrom, 1997 \\
\hline Daam1 & Actin organization & Aspenstrom et al., 2006 \\
\hline FMNL1 & Actin organization & Seth et al., 2006 \\
\hline IFN2 & Trafficking - trancytosis. & Madrid et al., 2010 \\
\hline FMNL2 & Actin organization & Block et al., 2012 \\
\hline IQGAP1 & Cell morphology and motility & Kuroda et al., 1996 \\
\hline IQGAP2 & Actin organization & $\begin{array}{l}\text { Kuroda et al., 1996; LeCour et } \\
\text { al., } 2016\end{array}$ \\
\hline IQGAP3 & Actin organization & Kuroda et al., 1996 \\
\hline IRSp53/BAIAP2 & Actin organization - filopodia induction & Krugmann et al., 2001 \\
\hline $\mathrm{mDia} 2 / \mathrm{DRF} 2$ & Actin organization & Alberts et al., 1998 \\
\hline mDia3 & Actin organization & Yasuda et al., 2004 \\
\hline Mig-6/RALT & Regulates cell migration & Jiang et al., 2016 \\
\hline MEKK1/MAP3K1 & JNK and ERK pathway activation & Fanger et al., 1997 \\
\hline MLK2/MAP3K10 & JNK and ERK pathway activation; microtubules & Nagata et al., 1998 \\
\hline MLK3 /MAP3K11 & JNK activation, microtubules & Nagata et al., 1998 \\
\hline MEKK4/MAP3K4 & CSBP2 and JNK activation & Fanger et al., 1997 \\
\hline
\end{tabular}




\begin{tabular}{|c|c|c|}
\hline $\mathrm{MRCK} \alpha / \mathrm{CDC} 42 \mathrm{BPA}$ & Actomyosin regulation & Leung et al., 1998 \\
\hline MRCK $\beta / C D C 42 B P B$ & Actomyosin regulation & Leung et al., 1998 \\
\hline MRCK $\gamma / \mathrm{CDC} 42 \mathrm{BPG}$ & Actomyosin regulation & Leung et al., 1998 \\
\hline MSE55 & Actin organization & Burbelo et al., 1999 \\
\hline N-WASP/WASL & Actin organization & Miki et al., 1998 \\
\hline PAK1 & Actin organization, apoptosis & Manser et al., 1994 \\
\hline PAK2 & Apoptosis, inhibition of cell growth & Gatti et al., 1999 \\
\hline PAK3 & Dendrite development & Bagrodia et al., 1998 \\
\hline PAK4 & $\begin{array}{l}\text { Actin organization, adherens junction, adhesion, } \\
\text { migration }\end{array}$ & Abo et al., 1998 \\
\hline PAK5 & Neurite development, microtubule stability & Dan et al., 2002 \\
\hline PAK6 & Actin organization, motility, adherens junction & Lee et al., 2002 \\
\hline PAR6A & Cell polarity & Joberty et al., 2000 \\
\hline PAR6B & Cell polarity & Joberty et al., 2000 \\
\hline PAR6G & Cell polarity & $\begin{array}{l}\text { Joberty et al., 2000; Johansson } \\
\text { et al., } 2000\end{array}$ \\
\hline $\mathrm{PIK} 3 \mathrm{R} 1 / \mathrm{p} 85 \alpha$ & Actin regulation, growth, motility, trafficking & Cheung et al., 2014 \\
\hline PLD1/phospholipase D1 & Phosphatidic acid levels, cytoskeleton & Walker et al., 2000 \\
\hline RPS6KB1/S6 kinase & Cell growth and proliferation & Chou and Blenis, 1996 \\
\hline SPEC1/CDC42SE1 & Actin organization, cell shape & Pirone et al., 2000 \\
\hline SPEC2/CDC42SE2 & Actin organization, cell shape & Pirone et al., 2000 \\
\hline USP6/TRE17 & Trafficking & Masuda-Robens et al., 2003 \\
\hline WASP & Actin organization & Symons et al., 1996 \\
\hline
\end{tabular}


Table S2. Cdc42 GEFs and GAPs in mammals.

Guanine nucleotide exchange factors (GEFs)

\begin{tabular}{l} 
Gene name \\
\hline ARHGEF4/Asef \\
ARHGEF6/Cool-2 \\
ARHGEF7//Pix/Cool-1
\end{tabular}

ARHGEF15/VsmRhoGEF/Ephexin5

CLG

DBL3

DBS

DOCK2

DOCK6

DOCK7

DOCK9/Zizimin 1

ECT2

FGD1

FGD2

FGD3

FGD4/FAB

\section{Function}

Dbl family of Rho GEFs - associated with

lamellipodia and membrane ruffles.

Dbl family of Rho GEFs - associated with PAK function.

Dbl family of Rho GEFs - associated with PAK function in focal adhesion complexes in COS cells. Also associates with Scribble to regulate epithelial morphogenesis.

Dbl family of Rho GEFs - mediates VEGFinduced retinal angiogenesis.

Dbl family of Rho GEFs - promotes growth in NIH 3 T3 cells.

Dbl family of Rho GEFs - regulates epithelial junction position and apical differentiation.

Dbl family of Rho GEFs - Schwann cell and tumor-derived, human breast epithelial cells migration.

CDM family of Rho GEFs - regulates neutrophil motility and polarity.

CDM family of Rho GEFs - regulates neurite outgrowth in mouse N1E-115 neuroblastoma cells, and axon extension in dorsal root ganglion neurons.

CDM family of Rho GEFs - induces dendritic pseudopodia in human cancer cell lines.

CDM family of Rho GEFs - induces filopodia in NIH-3T3 cells and dendrite growth in rat hippocampal neurons.

Dbl family of Rho GEFs - promotes glioma cell migration and invasion. Actomyosin remodeling during cell division. Promotes $\mathrm{PKC} \zeta$ activity in MDCK cells to regulate junction maturation.

Dbl family of Rho GEFs - induces the formation of filopodia in NIH-3T3 cells. Linked to

faciogenital dysplasia and to F-actin morphogenesis through Arp2/3.

Dbl family of Rho GEFs - associated with early endosomes and membrane ruffles.

Dbl family of Rho GEFs - induces broad sheetlike protrusions in HeLa cells.

Dbl family of Rho GEFs - associates with Factin. Induces filopodia like protrusions NIH$3 \mathrm{~T} 3$.

\section{Reference}

Gotthardt and Ahmadian, 2007;

Itoh et al., 2008; Kawasaki et

al., 2007

Baird et al., 2005

Bagrodia et al., 1998; Eastburn et al., 2012; Manser et al., 1998

Kusuhara et al., 2012

Himmel et al., 2002

Hart et al., 1991; Zihni et al., 2014

Liu et al., 2009; Yamauchi et al., 2005

Kunisaki et al., 2006; Kwofie and Skowronski, 2008

Miyamoto et al., 2013;

Miyamoto et al., 2007

Yamamoto et al., 2013

Kuramoto et al., 2009; Kwofie and Skowronski, 2008; Meller et al., 2002

Fortin et al., 2012; Liu et al., 2004; Rosa et al., 2015

Hou et al., 2003; Zheng et al., 1996

Huber et al., 2008

Hayakawa et al., 2008

Obaishi et al., 1998 
FGD5/FYVE

FRG

ITSN1

ITSN2

TUBA/KIAA1010/DNM BP/ArhGEF36

Vav3
Dbl family of Rho GEFs - associated with Cdc42 activation at the cell-cell contacts in HUVECS cells.

Dbl family of Rho GEFs - associated with nectin-based adhesion at the adherens junction in MDCK cells.

Dbl family of Rho GEFs -Associated to F-actin remodeling during exocytosis in neuroendocrine cells. Involved in tethering endocytic proteins to the sites of endocytosis.

Dbl family of Rho GEFs - Localized at the centrosome in MDCK spheroids. Promotes central lumen formation by regulating spindle orientation in MDCK spheroid. Regulates asymmetric meiotic divisions in mammalian oocyte through F-actin (WASp) regulation. WASp-binding protein associated with the endocytic pathway in T lymphocytes.

Dbl family of Rho GEFs - Localized at the tight junction through $\mathrm{ZO} 1$ in Caco-2cells, and in the vicinity of the apical membrane in MDCK spheroids. Enterocyte polarity, lumen formation, tight junction integrity and ciliogenesis.

Dbl family of Rho GEFs - Involved in integrinmediated signaling, wound healing, angiogenesis and neurite outgrowth.
Ando et al., 2013

Fukuhara et al., 2004; Miyamoto et al., 2003

Koh et al., 2004; Malacombe et al., 2006

McGavin et al., 2001;

Rodriguez-Fraticelli et al., 2010; Zhang et al., 2017

Baek et al., 2016; Kovacs et al., 2011; Otani et al., 2006; Qin et al., 2010

Zeng et al., 2000

GTPase-activating proteins

\begin{tabular}{l|l|l} 
Gene name & Function & Reference \\
\hline ARHGAP17/Rich1/ & $\begin{array}{l}\text { Localizes at the adherens junction and basal end } \\
\text { of the tight junction in MDCK cells. Linked to } \\
\text { epithelial junction regulation in MDCK } \\
\text { spheroids and in the mouse intestine. Linked to }\end{array}$ & $\begin{array}{l}\text { Harada et al., 2000; Lee et al., } \\
\text { 2016; Richnau and Aspenstrom, } \\
\text { 2001; Wells et al., 2006 }\end{array}$
\end{tabular}

\section{ARHGAP31/CdGAP}

ARHGAP33/NOMAGAP

DLC1/START-GAP1

DLC2/START-GAP2

RLIP

RACGAP1 spheroids and in the mouse intestine. Linked to transcellular transport in the intestine epithelium, in mice. Associated with endocytic actin capping proteins. Regulates exocytosis in neurons.

Regulates embryonic vascular development in mice. Regulates lamellipodia formation NIH $3 \mathrm{~T} 3$ cells and directional membrane protrusions of migrating osteosarcoma cells.

Regulates neurite formation and extension through PAK signaling.

Localized in focal adhesions in Hela cells. Regulates cell motility in cancer cell lines.

Localized in focal adhesions in Hela cells. Associated to hepatocarcinogenesis.

F-actin cytoskeleton regulation during Xenopus gastrulation.

Regulate the migration of hepatocyte-derived cells.
Caron et al., 2016; LamarcheVane and Hall, 1998

Rosario et al., 2007

Healy et al., 2008

Ching et al., 2003; Kawai et al., 2009

Jullien-Flores et al., 1995

Wang et al., 2011 
SH3BP1

Localized at the adherens junction and basal end Elbediwy et al., 2012

of the tight junction. Regulator of junction

assembly and epithelial morphogenesis in Caco-

2 spheroids.

\section{References}

Abo, A., Qu, J., Cammarano, M. S., Dan, C., Fritsch, A., Baud, V., Belisle, B. and Minden, A. (1998). PAK4, a novel effector for Cdc42Hs, is implicated in the reorganization of the actin cytoskeleton and in the formation of filopodia. Embo J 17, 6527-40.

Alberts, A. S., Bouquin, N., Johnston, L. H. and Treisman, R. (1998). Analysis of RhoA-binding proteins reveals an interaction domain conserved in heterotrimeric $\mathrm{G}$ protein beta subunits and the yeast response regulator protein Skn7. J Biol Chem 273, 8616-22.

Ando, K., Fukuhara, S., Moriya, T., Obara, Y., Nakahata, N. and Mochizuki, N. (2013). Rap1 potentiates endothelial cell junctions by spatially controlling myosin II activity and actin organization. $J$ Cell Biol 202, 901-16.

Aspenstrom, P. (1997). A Cdc42 target protein with homology to the non-kinase domain of FER has a potential role in regulating the actin cytoskeleton. Curr Biol 7, 479-87.

Aspenstrom, P., Richnau, N. and Johansson, A. S. (2006). The diaphanous-related formin DAAM1 collaborates with the Rho GTPases RhoA and Cdc42, CIP4 and Src in regulating cell morphogenesis and actin dynamics. Exp Cell Res 312, 2180-94.

Baek, J. I., Kwon, S. H., Zuo, X., Choi, S. Y., Kim, S. H. and Lipschutz, J. H. (2016). Dynamin Binding Protein (Tuba) Deficiency Inhibits Ciliogenesis and Nephrogenesis in Vitro and in Vivo. J Biol Chem 291, 8632-43.

Bagrodia, S., Taylor, S. J., Jordon, K. A., Van Aelst, L. and Cerione, R. A. (1998). A novel regulator of p21-activated kinases. J Biol Chem 273, 23633-6.

Baird, D., Feng, Q. and Cerione, R. A. (2005). The Cool-2/alpha-Pix protein mediates a Cdc42-Rac signaling cascade. Curr Biol 15, 1-10.

Block, J., Breitsprecher, D., Kuhn, S., Winterhoff, M., Kage, F., Geffers, R., Duwe, P., Rohn, J. L., Baum, B., Brakebusch, C. et al. (2012). FMNL2 drives actin-based protrusion and migration downstream of Cdc42. Curr Biol 22, 1005-12.

Burbelo, P. D., Snow, D. M., Bahou, W. and Spiegel, S. (1999). MSE55, a Cdc42 effector protein, induces long cellular extensions in fibroblasts. Proc Natl Acad Sci U S A 96, 9083-8.

Caron, C., DeGeer, J., Fournier, P., Duquette, P. M., Luangrath, V., Ishii, H., Karimzadeh, F., Lamarche-Vane, N. and Royal, I. (2016). CdGAP/ARHGAP31, a Cdc42/Rac1 GTPase regulator, is critical for vascular development and VEGF-mediated angiogenesis. Sci Rep 6, 27485.

Cheung, L. W., Yu, S., Zhang, D., Li, J., Ng, P. K., Panupinthu, N., Mitra, S., Ju, Z., Yu, Q., Liang, H. et al. (2014). Naturally occurring neomorphic PIK3R1 mutations activate the MAPK pathway, dictating therapeutic response to MAPK pathway inhibitors. Cancer Cell 26, 479-94.

Ching, Y. P., Wong, C. M., Chan, S. F., Leung, T. H., Ng, D. C., Jin, D. Y. and Ng, I. O. (2003). Deleted in liver cancer (DLC) 2 encodes a RhoGAP protein with growth suppressor function and is underexpressed in hepatocellular carcinoma. J Biol Chem 278, 10824-30.

Chou, M. M. and Blenis, J. (1996). The $70 \mathrm{kDa}$ S6 kinase complexes with and is activated by the Rho family G proteins Cdc42 and Rac1. Cell 85, 573-83.

Dan, C., Nath, N., Liberto, M. and Minden, A. (2002). PAK5, a new brain-specific kinase, promotes neurite outgrowth in N1E-115 cells. Mol Cell Biol 22, 567-77.

Eastburn, D. J., Zegers, M. M. and Mostov, K. E. (2012). Scrib regulates HGF-mediated epithelial morphogenesis and is stabilized by Sgt1-HSP90. J Cell Sci 125, 4147-57.

Elbediwy, A., Zihni, C., Terry, S. J., Clark, P., Matter, K. and Balda, M. S. (2012). Epithelial junction formation requires confinement of Cdc42 activity by a novel SH3BP1 complex. J Cell Biol 198, 677-93.

Fanger, G. R., Johnson, N. L. and Johnson, G. L. (1997). MEK kinases are regulated by EGF and selectively interact with Rac/Cdc42. Embo J 16, 4961-72.

Fortin, S. P., Ennis, M. J., Schumacher, C. A., Zylstra-Diegel, C. R., Williams, B. O., Ross, J. T., Winkles, J. A., Loftus, J. C., Symons, M. H. and Tran, N. L. (2012). Cdc42 and the guanine nucleotide exchange factors Ect2 and trio mediate Fn14-induced migration and invasion of glioblastoma cells. Mol Cancer Res 10, 958-68. 
Fukuhara, T., Shimizu, K., Kawakatsu, T., Fukuyama, T., Minami, Y., Honda, T., Hoshino, T., Yamada, T., Ogita, H., Okada, M. et al. (2004). Activation of Cdc42 by trans interactions of the cell adhesion molecules nectins through c-Src and Cdc42-GEF FRG. J Cell Biol 166, 393-405.

Gatti, A., Huang, Z., Tuazon, P. T. and Traugh, J. A. (1999). Multisite autophosphorylation of p21activated protein kinase gamma-PAK as a function of activation. $J$ Biol Chem 274, 8022-8.

Gotthardt, K. and Ahmadian, M. R. (2007). Asef is a Cdc42-specific guanine nucleotide exchange factor. Biol Chem 388, 67-71.

Harada, A., Furuta, B., Takeuchi, K., Itakura, M., Takahashi, M. and Umeda, M. (2000). Nadrin, a novel neuron-specific GTPase-activating protein involved in regulated exocytosis. J Biol Chem 275, 36885-91.

Hart, M. J., Eva, A., Evans, T., Aaronson, S. A. and Cerione, R. A. (1991). Catalysis of guanine nucleotide exchange on the CDC42Hs protein by the dbl oncogene product. Nature 354, 311-4.

Hayakawa, M., Matsushima, M., Hagiwara, H., Oshima, T., Fujino, T., Ando, K., Kikugawa, K., Tanaka, H., Miyazawa, K. and Kitagawa, M. (2008). Novel insights into FGD3, a putative GEF for $\mathrm{Cdc} 42$, that undergoes SCF(FWD1/beta-TrCP)-mediated proteasomal degradation analogous to that of its homologue FGD1 but regulates cell morphology and motility differently from FGD1. Genes Cells 13, $329-42$.

Healy, K. D., Hodgson, L., Kim, T. Y., Shutes, A., Maddileti, S., Juliano, R. L., Hahn, K. M., Harden, T. K., Bang, Y. J. and Der, C. J. (2008). DLC-1 suppresses non-small cell lung cancer growth and invasion by RhoGAP-dependent and independent mechanisms. Mol Carcinog 47, 326-37.

Himmel, K. L., Bi, F., Shen, H., Jenkins, N. A., Copeland, N. G., Zheng, Y. and Largaespada, D. A. (2002). Activation of clg, a novel dbl family guanine nucleotide exchange factor gene, by proviral insertion at evi24, a common integration site in B cell and myeloid leukemias. J Biol Chem 277, 1346372.

Hirsch, D. S., Pirone, D. M. and Burbelo, P. D. (2001). A new family of Cdc42 effector proteins, CEPs, function in fibroblast and epithelial cell shape changes. $J$ Biol Chem 276, 875-83.

Hou, P., Estrada, L., Kinley, A. W., Parsons, J. T., Vojtek, A. B. and Gorski, J. L. (2003). Fgd1, the Cdc42 GEF responsible for Faciogenital Dysplasia, directly interacts with cortactin and mAbp1 to modulate cell shape. Hum Mol Genet 12, 1981-93.

Huber, C., Martensson, A., Bokoch, G. M., Nemazee, D. and Gavin, A. L. (2008). FGD2, a CDC42specific exchange factor expressed by antigen-presenting cells, localizes to early endosomes and active membrane ruffles. $J$ Biol Chem 283, 34002-12.

Itoh, R. E., Kiyokawa, E., Aoki, K., Nishioka, T., Akiyama, T. and Matsuda, M. (2008). Phosphorylation and activation of the Rac1 and Cdc42 GEF Asef in A431 cells stimulated by EGF. $J$ Cell Sci 121, 2635-42.

Jiang, X., Niu, M., Chen, D., Chen, J., Cao, Y., Li, X., Ying, H., Bergholz, J., Zhang, Y. and Xiao, Z. X. (2016). Inhibition of Cdc42 is essential for Mig-6 suppression of cell migration induced by EGF. Oncotarget 7, 49180-49193.

Joberty, G., Perlungher, R. R. and Macara, I. G. (1999). The Borgs, a new family of Cdc42 and TC10 GTPase-interacting proteins. Mol Cell Biol 19, 6585-97.

Joberty, G., Perlungher, R. R., Sheffield, P. J., Kinoshita, M., Noda, M., Haystead, T. and Macara, I. G. (2001). Borg proteins control septin organization and are negatively regulated by Cdc42. Nat Cell Biol 3, 861-6.

Joberty, G., Petersen, C., Gao, L. and Macara, I. G. (2000). The cell-polarity protein Par6 links Par3 and atypical protein kinase C to Cdc42. Nat Cell Biol 2, 531-9.

Johansson, A., Driessens, M. and Aspenstrom, P. (2000). The mammalian homologue of the Caenorhabditis elegans polarity protein PAR-6 is a binding partner for the Rho GTPases Cdc42 and Rac1. J Cell Sci 113 ( Pt 18), 3267-75.

Jullien-Flores, V., Dorseuil, O., Romero, F., Letourneur, F., Saragosti, S., Berger, R., Tavitian, A., Gacon, G. and Camonis, J. H. (1995). Bridging Ral GTPase to Rho pathways. RLIP76, a Ral effector with CDC42/Rac GTPase-activating protein activity. J Biol Chem 270, 22473-7.

Kawai, K., Seike, J., Iino, T., Kiyota, M., Iwamae, Y., Nishitani, H. and Yagisawa, H. (2009). STARTGAP2/DLC2 is localized in focal adhesions via its N-terminal region. Biochem Biophys Res Commun 380, 736-41.

Kawasaki, Y., Sagara, M., Shibata, Y., Shirouzu, M., Yokoyama, S. and Akiyama, T. (2007). Identification and characterization of Asef2, a guanine-nucleotide exchange factor specific for Rac1 and Cdc42. Oncogene 26, 7620-267. 
Koh, T. W., Verstreken, P. and Bellen, H. J. (2004). Dap160/intersectin acts as a stabilizing scaffold required for synaptic development and vesicle endocytosis. Neuron 43, 193-205.

Kovacs, E. M., Verma, S., Thomas, S. G. and Yap, A. S. (2011). Tuba and N-WASP function cooperatively to position the central lumen during epithelial cyst morphogenesis. Cell Adh Migr 5, 34450.

Krugmann, S., Jordens, I., Gevaert, K., Driessens, M., Vandekerckhove, J. and Hall, A. (2001). Cdc42 induces filopodia by promoting the formation of an IRSp53:Mena complex. Curr Biol 11, 1645-55.

Kunisaki, Y., Nishikimi, A., Tanaka, Y., Takii, R., Noda, M., Inayoshi, A., Watanabe, K., Sanematsu, F., Sasazuki, T., Sasaki, T. et al. (2006). DOCK2 is a Rac activator that regulates motility and polarity during neutrophil chemotaxis. J Cell Biol 174, 647-52.

Kuroda, S., Fukata, M., Kobayashi, K., Nakafuku, M., Nomura, N., Iwamatsu, A. and Kaibuchi, K. (1996). Identification of IQGAP as a putative target for the small GTPases, Cdc42 and Rac1. J Biol Chem 271, 23363-7.

Kuramoto, K., Negishi, M. and Katoh, H. (2009). Regulation of dendrite growth by the Cdc42 activator Zizimin1/Dock9 in hippocampal neurons. J Neurosci Res 87, 1794-805.

Kusuhara, S., Fukushima, Y., Fukuhara, S., Jakt, L. M., Okada, M., Shimizu, Y., Hata, M., Nishida, K., Negi, A., Hirashima, M. et al. (2012). Arhgef15 promotes retinal angiogenesis by mediating VEGFinduced Cdc42 activation and potentiating RhoJ inactivation in endothelial cells. PLoS One 7, e45858.

Kwofie, M. A. and Skowronski, J. (2008). Specific recognition of Rac2 and Cdc42 by DOCK 2 and DOCK9 guanine nucleotide exchange factors. J Biol Chem 283, 3088-96.

Lamarche-Vane, N. and Hall, A. (1998). CdGAP, a novel proline-rich GTPase-activating protein for Cdc42 and Rac. J Biol Chem 273, $29172-7$.

LeCour, L., Jr., Boyapati, V. K., Liu, J., Li, Z., Sacks, D. B. and Worthylake, D. K. (2016). The Structural Basis for Cdc42-Induced Dimerization of IQGAPs. Structure 24, 1499-508.

Lee, S. R., Ramos, S. M., Ko, A., Masiello, D., Swanson, K. D., Lu, M. L. and Balk, S. P. (2002). AR and ER interaction with a p21-activated kinase (PAK6). Mol Endocrinol 16, 85-99.

Lee, S. Y., Kim, H., Kim, K., Lee, H., Lee, S. and Lee, D. (2016). Arhgap17, a RhoGTPase activating protein, regulates mucosal and epithelial barrier function in the mouse colon. Sci Rep 6, 26923.

Leung, T., Chen, X. Q., Tan, I., Manser, E. and Lim, L. (1998). Myotonic dystrophy kinase-related Cdc42-binding kinase acts as a Cdc42 effector in promoting cytoskeletal reorganization. Mol Cell Biol 18, 130-40.

Liu, X. F., Ishida, H., Raziuddin, R. and Miki, T. (2004). Nucleotide exchange factor ECT2 interacts with the polarity protein complex Par6/Par3/protein kinase Czeta (PKCzeta) and regulates PKCzeta activity. Mol Cell Biol 24, 6665-75.

Liu, Z., Adams, H. C., 3rd and Whitehead, I. P. (2009). The rho-specific guanine nucleotide exchange factor Dbs regulates breast cancer cell migration. J Biol Chem 284, 15771-80.

Madrid, R., Aranda, J. F., Rodriguez-Fraticelli, A. E., Ventimiglia, L., Andres-Delgado, L., Shehata, M., Fanayan, S., Shahheydari, H., Gomez, S., Jimenez, A. et al. (2010). The formin INF2 regulates basolateral-to-apical transcytosis and lumen formation in association with Cdc42 and MAL2. Dev Cell 18, 814-27.

Malacombe, M., Ceridono, M., Calco, V., Chasserot-Golaz, S., McPherson, P. S., Bader, M. F. and Gasman, S. (2006). Intersectin-1L nucleotide exchange factor regulates secretory granule exocytosis by activating Cdc42. Embo J 25, 3494-503.

Manser, E., Leung, T., Salihuddin, H., Tan, L. and Lim, L. (1993). A non-receptor tyrosine kinase that inhibits the GTPase activity of p21cdc42. Nature 363, 364-7.

Manser, E., Leung, T., Salihuddin, H., Zhao, Z. S. and Lim, L. (1994). A brain serine/threonine protein kinase activated by Cdc42 and Rac1. Nature 367, 40-6.

Manser, E., Loo, T. H., Koh, C. G., Zhao, Z. S., Chen, X. Q., Tan, L., Tan, I., Leung, T. and Lim, L. (1998). PAK kinases are directly coupled to the PIX family of nucleotide exchange factors. Mol Cell $\mathbf{1}$, $183-92$.

Masuda-Robens, J. M., Kutney, S. N., Qi, H. and Chou, M. M. (2003). The TRE17 oncogene encodes a component of a novel effector pathway for Rho GTPases Cdc42 and Rac1 and stimulates actin remodeling. Mol Cell Biol 23, 2151-61.

McGavin, M. K., Badour, K., Hardy, L. A., Kubiseski, T. J., Zhang, J. and Siminovitch, K. A. (2001). The intersectin 2 adaptor links Wiskott Aldrich Syndrome protein (WASp)-mediated actin polymerization to T cell antigen receptor endocytosis. J Exp Med 194, 1777-87. 
Meller, N., Irani-Tehrani, M., Kiosses, W. B., Del Pozo, M. A. and Schwartz, M. A. (2002). Zizimin1, a novel Cdc42 activator, reveals a new GEF domain for Rho proteins. Nat Cell Biol 4, 639-47.

Miki, H., Sasaki, T., Takai, Y. and Takenawa, T. (1998). Induction of filopodium formation by a WASPrelated actin-depolymerizing protein N-WASP. Nature 391, 93-6.

Miyamoto, Y., Torii, T., Yamamori, N., Ogata, T., Tanoue, A. and Yamauchi, J. (2013). Akt and PP2A reciprocally regulate the guanine nucleotide exchange factor Dock6 to control axon growth of sensory neurons. Sci Signal 6, ra15.

Miyamoto, Y., Yamauchi, J. and Itoh, H. (2003). Src kinase regulates the activation of a novel FGD-1related $\mathrm{Cdc} 42$ guanine nucleotide exchange factor in the signaling pathway from the endothelin $\mathrm{A}$ receptor to JNK. J Biol Chem 278, 29890-900.

Miyamoto, Y., Yamauchi, J., Sanbe, A. and Tanoue, A. (2007). Dock6, a Dock-C subfamily guanine nucleotide exchanger, has the dual specificity for Rac1 and Cdc42 and regulates neurite outgrowth. Exp Cell Res 313, 791-804.

Nagata, K., Puls, A., Futter, C., Aspenstrom, P., Schaefer, E., Nakata, T., Hirokawa, N. and Hall, A. (1998). The MAP kinase kinase kinase MLK2 co-localizes with activated JNK along microtubules and associates with kinesin superfamily motor KIF3. Embo J 17, 149-58.

Obaishi, H., Nakanishi, H., Mandai, K., Satoh, K., Satoh, A., Takahashi, K., Miyahara, M., Nishioka, H., Takaishi, K. and Takai, Y. (1998). Frabin, a novel FGD1-related actin filament-binding protein capable of changing cell shape and activating c-Jun N-terminal kinase. J Biol Chem 273, 18697-700.

Otani, T., Ichii, T., Aono, S. and Takeichi, M. (2006). Cdc42 GEF Tuba regulates the junctional configuration of simple epithelial cells. J Cell Biol 175, 135-46.

Pirone, D. M., Fukuhara, S., Gutkind, J. S. and Burbelo, P. D. (2000). SPECs, small binding proteins for Cdc42. J Biol Chem 275, 22650-6.

Qin, Y., Meisen, W. H., Hao, Y. and Macara, I. G. (2010). Tuba, a Cdc42 GEF, is required for polarized spindle orientation during epithelial cyst formation. J Cell Biol 189, 661-9.

Richnau, N. and Aspenstrom, P. (2001). Rich, a rho GTPase-activating protein domain-containing protein involved in signaling by Cdc42 and Rac1. J Biol Chem 276, 35060-70.

Rodriguez-Fraticelli, A. E., Vergarajauregui, S., Eastburn, D. J., Datta, A., Alonso, M. A., Mostov, K. and Martin-Belmonte, F. (2010). The Cdc42 GEF Intersectin 2 controls mitotic spindle orientation to form the lumen during epithelial morphogenesis. J Cell Biol 189, 725-38.

Rosa, A., Vlassaks, E., Pichaud, F. and Baum, B. (2015). Ect2/Pbl acts via Rho and polarity proteins to direct the assembly of an isotropic actomyosin cortex upon mitotic entry. Dev Cell 32, 604-16.

Rosario, M., Franke, R., Bednarski, C. and Birchmeier, W. (2007). The neurite outgrowth multiadaptor RhoGAP, NOMA-GAP, regulates neurite extension through SHP2 and Cdc42. J Cell Biol 178, 503-16.

Seth, A., Otomo, C. and Rosen, M. K. (2006). Autoinhibition regulates cellular localization and actin assembly activity of the diaphanous-related formins FRLalpha and mDia1. J Cell Biol 174, 701-13.

Symons, M., Derry, J. M., Karlak, B., Jiang, S., Lemahieu, V., McCormick, F., Francke, U. and Abo, A. (1996). Wiskott-Aldrich syndrome protein, a novel effector for the GTPase CDC42Hs, is implicated in actin polymerization. Cell $\mathbf{8 4}, 723-34$.

Walker, S. J., Wu, W. J., Cerione, R. A. and Brown, H. A. (2000). Activation of phospholipase D1 by Cdc42 requires the Rho insert region. J Biol Chem 275, 15665-8.

Wang, S. M., Ooi, L. L. and Hui, K. M. (2011). Upregulation of Rac GTPase-activating protein 1 is significantly associated with the early recurrence of human hepatocellular carcinoma. Clin Cancer Res 17, 6040-51.

Wells, C. D., Fawcett, J. P., Traweger, A., Yamanaka, Y., Goudreault, M., Elder, K., Kulkarni, S., Gish, G., Virag, C., Lim, C. et al. (2006). A Rich1/Amot complex regulates the Cdc42 GTPase and apical-polarity proteins in epithelial cells. Cell 125, 535-48.

Yamamoto, K., Murata, H., Putranto, E. W., Kataoka, K., Motoyama, A., Hibino, T., Inoue, Y., Sakaguchi, M. and Huh, N. H. (2013). DOCK7 is a critical regulator of the RAGE-Cdc42 signaling axis that induces formation of dendritic pseudopodia in human cancer cells. Oncol Rep 29, 1073-9.

Yamauchi, J., Chan, J. R., Miyamoto, Y., Tsujimoto, G. and Shooter, E. M. (2005). The neurotrophin-3 receptor TrkC directly phosphorylates and activates the nucleotide exchange factor Dbs to enhance Schwann cell migration. Proc Natl Acad Sci U S A 102, 5198-203.

Yasuda, S., Oceguera-Yanez, F., Kato, T., Okamoto, M., Yonemura, S., Terada, Y., Ishizaki, T. and Narumiya, S. (2004). Cdc42 and mDia3 regulate microtubule attachment to kinetochores. Nature 428, $767-71$. 
Zeng, L., Sachdev, P., Yan, L., Chan, J. L., Trenkle, T., McClelland, M., Welsh, J. and Wang, L. H. (2000). Vav3 mediates receptor protein tyrosine kinase signaling, regulates GTPase activity, modulates cell morphology, and induces cell transformation. Mol Cell Biol 20, 9212-24.

Zhang, J., Ma, R., Li, L., Wang, L., Hou, X., Han, L., Ge, J., Li, M. and Wang, Q. (2017). Intersectin 2 controls actin cap formation and meiotic division in mouse oocytes through the Cdc42 pathway. Faseb $J$ 31, 4277-4285.

Zheng, Y., Fischer, D. J., Santos, M. F., Tigyi, G., Pasteris, N. G., Gorski, J. L. and Xu, Y. (1996). The faciogenital dysplasia gene product FGD1 functions as a Cdc42Hs-specific guanine-nucleotide exchange factor. J Biol Chem 271, 33169-72.

Zihni, C., Munro, P. M., Elbediwy, A., Keep, N. H., Terry, S. J., Harris, J., Balda, M. S. and Matter, K. (2014). Dbl3 drives Cdc42 signaling at the apical margin to regulate junction position and apical differentiation. J Cell Biol 204, 111-27. 